\title{
Response Of Ovine Neutrophils To Different Life Stages Of Haemonchus Contortus
}

\author{
Denzel Deshawn Middleton
}

Follow this and additional works at: https://researchrepository.wvu.edu/etd

\section{Recommended Citation}

Middleton, Denzel Deshawn, "Response Of Ovine Neutrophils To Different Life Stages Of Haemonchus Contortus" (2018). Graduate Theses, Dissertations, and Problem Reports. 7214.

https://researchrepository.wvu.edu/etd/7214

This Thesis is protected by copyright and/or related rights. It has been brought to you by the The Research Repository @ WVU with permission from the rights-holder(s). You are free to use this Thesis in any way that is permitted by the copyright and related rights legislation that applies to your use. For other uses you must obtain permission from the rights-holder(s) directly, unless additional rights are indicated by a Creative Commons license in the record and/ or on the work itself. This Thesis has been accepted for inclusion in WVU Graduate Theses, Dissertations, and Problem Reports collection by an authorized administrator of The Research Repository @ WVU. For more information, please contact researchrepository@mail.wvu.edu. 


\title{
RESPONSE OF OVINE NEUTROPHILS TO DIFFERENT LIFE STAGES OF HAEMONCHUS CONTORTUS
}

\author{
Denzel Deshawn Middleton
}

Thesis submitted to the Davis College of Agriculture, Natural Resources and Design at West Virginia University in partial fulfillment of the requirements for the degree of

Master of Science in Animal Physiology

\author{
Scott A. Bowdridge, Ph.D., Chair \\ Jianbo Yao, Ph.D. \\ Daniel J. Mathew, Ph.D.
}

Division of Animal and Nutritional Sciences

Morgantown, West Virginia

2018

Keywords: $H$. contortus, Neutrophils, Th2 response

Copyright 2018 Denzel Middleton 


\section{Abstract \\ RESPONSE OF OVINE NEUTROPHILS TO DIFFERENT LIFE STAGES OF HAEMONCHUS CONTORTUS \\ Denzel Middleton}

Initiation of immune responses to helminth infection require interleukin (IL) -4 receptor signaling, activating signal transducer and activation of transcription 6 (STAT6) and resulting in elevated IL4 and -13 production. This phenomenon occurs during early Haemonchus contortus $(H$. contortus) infection in parasite-resistant St. Croix (STC) sheep, yet the cell responsible for early cytokine production is unknown. Studies have reported greater infiltration of neutrophils to the abomasum of STC by 3 days after $H$. contortus infection as compared to parasite-susceptible Suffolk sheep (SUF). Neutrophils have been noted to play a role in immune responses to murine helminth infections through production of IL-13, which promotes alternative macrophage polarization. Thus, it is reasonable to hypothesize that neutrophils are an early source of IL-4/IL-13 that promote resistance to $H$. contortus infection. This study aimed to determine differences in ovine neutrophil responses when stimulated with antigen (Ag) from larval and adult stages of $H$. contortus. Neutrophils from STC and SUF sheep were cultured with either larval (HcLA) or adult (HcWA) antigen. In vitro production of (IL-4/IL-13) cytokine were measured using an ovine-specific enzyme-linked immunosorbent assay (ELISA). Neutrophils from either breed exposed to HcLA produced significantly higher levels of IL-4 by 30 minutes (STC, $3153.65 \mathrm{pg} / \mathrm{ml}$ and SUF, 4665.22 $\mathrm{pg} / \mathrm{ml}$ ) and IL-13 by 6 hours (STC, $391.02 \mathrm{pg} / \mathrm{ml}$ and SUF, $419.6 \mathrm{pg} / \mathrm{ml}$ ) when compared to neutrophils cultured with HcWA (STC IL-4, $6.04 \mathrm{pg} / \mathrm{ml}$ and SUF, $8.05 \mathrm{pg} / \mathrm{ml}$, respectively) (STC $\mathrm{IL}-13,10 \mathrm{pg} / \mathrm{ml}$ and $12.5 \mathrm{pg} / \mathrm{ml})(\mathrm{P}<0.001)$. While no breed differences were observed, these data indicate that neutrophils preferentially respond to HcLA compared to HcWA. Taken together these data indicate that neutrophils are a potential effector cell responsible for initiating early Th2 responses during $H$. contortus infection in sheep. 


\section{Acknowledgements}

I would like to thank my advisor Dr. Bowdridge for taking a chance and giving me the opportunity to step out of my comfort zone and try something new on the whim. I have learned so much about workmanship and myself throughout my journey here at WVU and I would have to owe a lot of it to my advisor for pushing me to try things that I would have never done had I not been given this opportunity. I have learned so much from Dr. Bowdridge both in and out of the lab and it has made me both a better scientist and an overall better productive adult. I am truly grateful for this opportunity.

I would like to also thank Dr. Javier Garza for his undying belief in my abilities to succeed as a scientist. There were many times in which I felt inadequate as a scientist and with the challenge from Dr. Garza to think outside of the box and finesse my critical thinking abilities has helped me to grow as a scientist. I am forever grateful for what you see in me and the constant energy you put into pushing me to continue to ask questions and answer them.

To my labmates Jesica Jacobs, Taylor Harrison, Elizabeth Shepherd, Brynnan Russ, Andrew Weaver, Camren Maierle, and Reese Tuckwiller thank you for always being there to assist when help was needed and thank you for being a family away from home. This process is anything but easy, but you guys make the process a positive experience.

Lastly, I would like to express how grateful I am for the constant love and support that I receive from my family. My parents Raquel and Lloyd and step dad Boris have stuck by me throughout every decision made along this journey without question. My brothers and sisters have also lent a listening ear a time or two over the course of the process, even without knowing what I was talking about, they would just listen and say everything will be ok. Thank you all for your love and support, I love you all. 


\section{Table of Contents}

Chapter 1: Literature Review ............................................................................ 1

Introduction

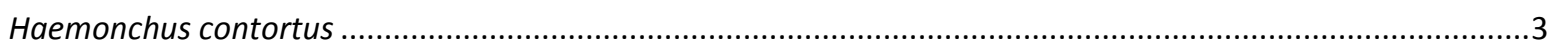

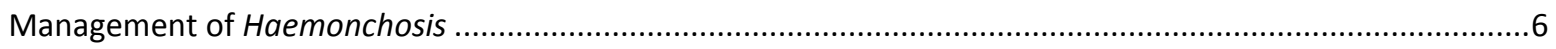

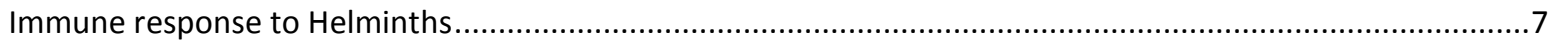

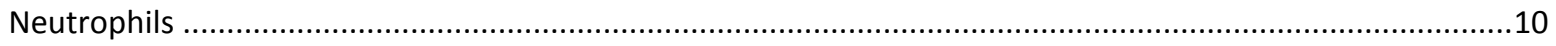

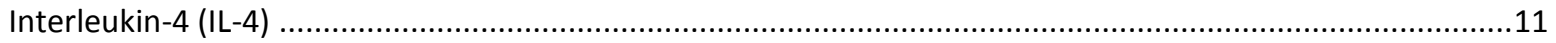

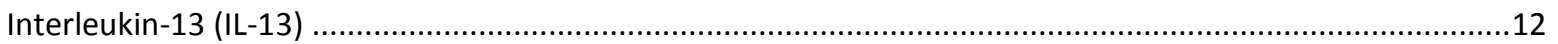

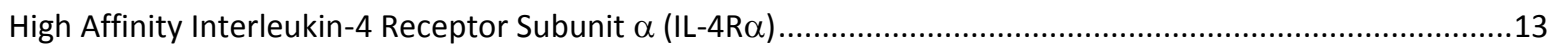

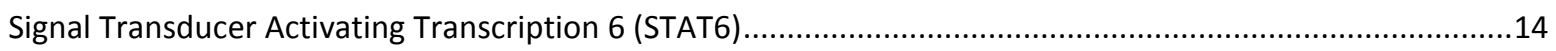

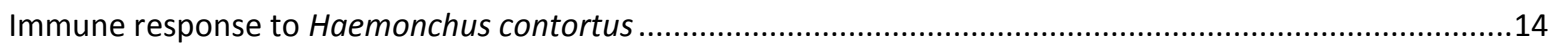

Chapter 2: Materials and Methods..................................................................................... 18

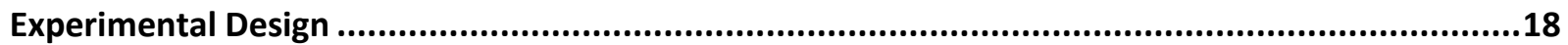

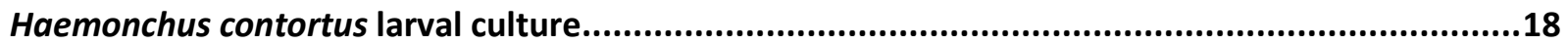

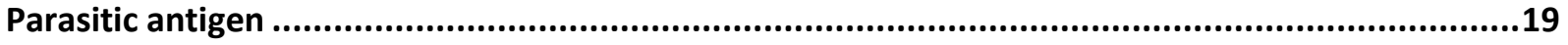

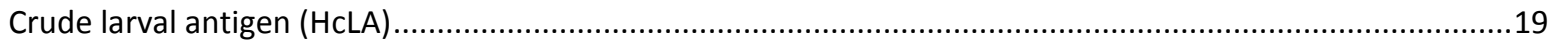

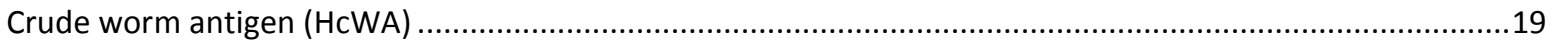

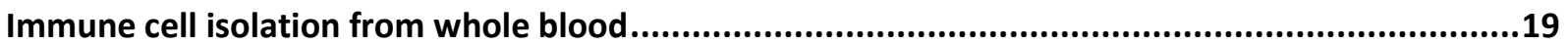

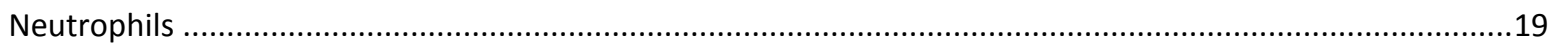

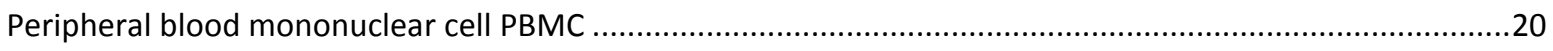

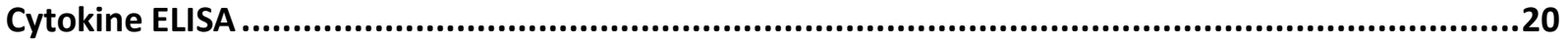

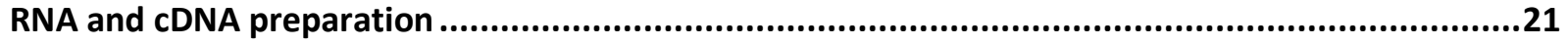

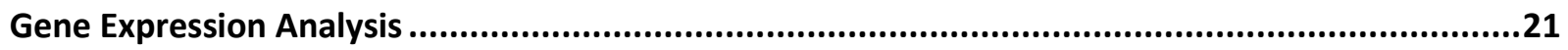

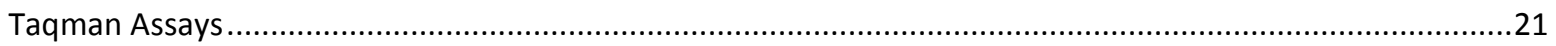

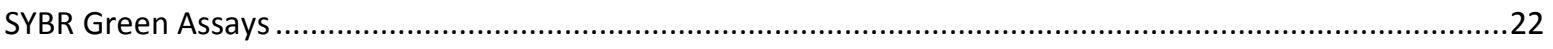

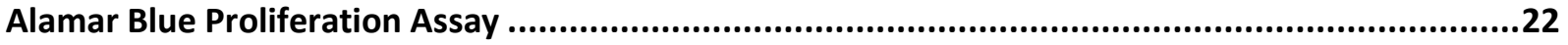

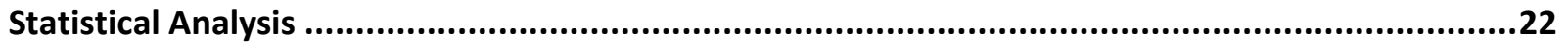

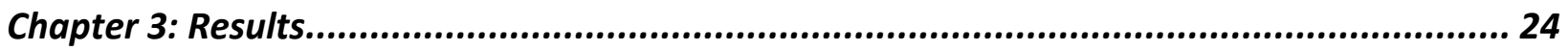

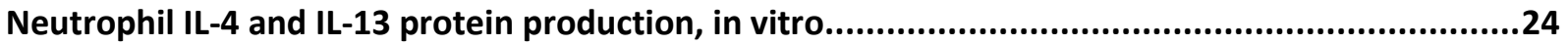

Neutrophil gene expression after $\boldsymbol{H}$. contortus antigen stimulation ............................................25

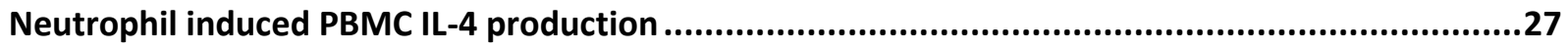

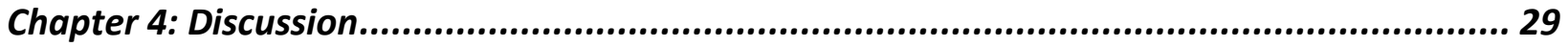




\section{List of Figures}

Figure 1. Model of resistance to $H$. contortus infection in sheep

Figure 2. Neutrophil IL-4 and IL-13 production in response to stimulation with larval (HcLA) or adult (HcWA) antigen

Figure 3. Neutrophil gene expression after exposure to H. contortus larval (HcLA) or adult (HcWA) antigen

Figure 4. mRNA analysis of primed Suffolk and primed St. Croix neutrophils by qPCR in response to culture with parasitic antigen

Figure 5. Interleukin-4 production by peripheral blood mononuclear cells (PBMC) stimulated with supernatant from $H$. contortus antigen stimulated neutrophils

Figure 6. Antigen primed neutrophils co-incubated with naïve PBMC to assess PBMC IL-4 production

Figure 7. STAT6 inhibition of primed St. Croix neutrophils

Figure 8. Proliferation assay to assess PBMC responsiveness after culture with $H$. contortus antigen stimulated neutrophils 


\section{List of Tables}

Table 1. Taqman probes

Table 2. SYBR Green primers 


\section{Chapter 1: Literature Review Introduction}

Gastrointestinal parasites are a source of immense economical loss in small ruminant production worldwide. In the United States, Haemonchus contortus has been one of the most reported gastrointestinal nematode (GIN) on infected pasture. Anthelmintic overuse has led to resistance in parasitic helminths (Howell et al., 2008). In the United States, sheep and goat farms in the southeast reported Haemonchus to have resistance to all drug classes (Howell et al., 2008). Lack of anthelmintic efficacy, has led producers to explore alternative strategies to control GIN infection. One particular strategy that has garnered interest is the use of parasite-resistant sheep breeds. St. Croix (STC) sheep have a unique ability to clear Haemonchus infection without anthelmintic treatment. Alternatively, commercial and economically relevant breeds such as Suffolk (SUF) sheep, fail to respond to larval stages without the use of anthelmintic, perpetuating adverse symptoms associated with helminth infection (Alba-Hurtado and Munoz-Guzman, 2013). Immunosuppressing genetically resistant Merino sheep with dexamethasone resulted in a susceptible phenotype, characterized by increased egg per gram (g) and total worm burden (Presson et al., 1988). Thus, elucidation of immune mechanisms favoring resistant phenotype during $H$. contortus infection is essential for advancing therapeutics.

T-helper type 2 (Th2) immune activation to helminth larval stages results in reduction of adult establishment and fecundity. Innate immune cell influx (eosinophils, mast cells, globule leukocytes), cytokine production (IL-4, IL-5, IL-13), and increased parasite-specific antibody (immunoglobulin A (IgA), IgE) production are all implicated in parasite expulsion (Balic et al., 2000, Lacroux et al., 2006). The abomasal environment during a Th2 response is characterized by increased luminal flow and intestinal muscle contractility, responses driven by IL-4 and IL-13 
cytokines (Harris et al., 2011). Interleukins 4 and 13 are hallmark cytokines of Th2-associated disease, both signal through Interleukin-4 receptor (IL-4R), and exhibit a vast array of functions in regulating inflammation (Iademarco et al., 1995; Wynn, 2003).

Previous studies have demonstrated a correlation between elevated IL-4 and IL-13 expression during early infection and prevention of parasite establishment. IL-4 expression was detected in STC abomasal tissue within the first 7 days of infection, but not until 10 days post infection (DPI) in SUF sheep (Jacobs et al., 2016).. At 10 DPI, IL-4 expression in STC abomasal tissue was absent, suggesting a delay in SUF ability to produce IL-4 transcript at the site of infection (Jacobs et al., 2016). IL-13 expression at 3 DPI was significantly increased in both STC abomasa and lymph node tissue, but was markedly reduced in susceptible sheep (MacKinnon et al., 2015). Delayed IL-4 expression and reduced IL-13 expression in SUF sheep reflects an inadequate host response to $H$. contortus larval stages, which permits establishment of adults and perpetuates their susceptible phenotype. Despite necessity for IL-4 and IL-13 in generating Th2 responses, the early effector source of these cytokines remains unknown. Bowdridge et al. (2015) identified cellular infiltrates of abomasal tissue during the first 7 days of $H$. contortus infection and found an increase of abomasal neutrophil accumulation in STC when compared to Dorset $\mathrm{x}$ Finn x Rambouillet sheep at 3 DPI. Ovine neutrophil ability to produce cytokines and interact with other immune cells remains to be further elucidated.

Thus, the focus of experiments conducted in this thesis was to investigate the role of neutrophils in the host protective immune response to $H$. contortus infection in STC sheep. The emphasis remained on neutrophil cytokine production and cellular communication. Interleukin-4 and IL-13 production within the first six hours of Haemonchus antigen stimulation of neutrophils 
in vitro was assessed. Neutrophil cellular communication and activation with both adaptive and innate cells were furthermore investigated.

\section{$\underline{\text { Haemonchus contortus }}$}

Haemonchus contortus is an enteric parasite commonly known as the "barber-pole worm" and belongs to the order Strongylida. Haemonchus is a member of the Trichostrongyloidea family (Mortensen et al., 2003). The barber-pole appearance is common for adult females because their white ovaries are wrapped around their blood-filled intestines. Males are between 10-20 mm in length while females are about $18-30 \mathrm{~mm}$ in length (Florian, 2013). Female adults are able to produce anywhere from 5,000 to 10,000 eggs per day within the abomasum of its host. The presence of a small, specialized buccal lancet on the end of fourth stage larvae (L4) and adults mouth, allows the worm to pierce the mucosal lining of the host's abomasum and feed on the host's blood (Gibbs, 1973). Haemonchosis is most prevalent in tropical and sub-tropical regions under warm and wet conditions.

Haemonchus contortus has a direct life cycle, which takes 14-21 days from egg to mature adult (Machen, 1914). Throughout their life cycle $H$. contortus larvae undergo five stages of development separated by structural changes. The first two stages and part of the third stage are non-parasitic and occur outside of the host, while L4 and L5 stages occur within the abomasum of the host and are parasitic in nature. Outside of the host, larvae are considered free living. Each larval stage can be split into sub stages with the first being a more active stage and the second being a lethargic stage (Veglia, 1916). The lethargic stage is the period of rest before initiating molting into the next stage of development (Veglia, 1916). 
Adult male and female $H$. contortus reside in the abomasum of small ruminants, where sexual reproduction occurs. Following reproduction, gravid females lay eggs, which are passed through feces into the environment. Larval development is highly dependent on environmental temperature and moisture level. Optimal temperatures for egg hatch and larval development are between $20^{\circ}$ and $35^{\circ} \mathrm{C}$. Egg hatch occurs under warm and moist conditions, if in soil, eggs hatch and L1 are released into the environment (Browning, 2006). Free-living L1 are active in soil, engaging in sinusoidal movement and they are equipped with a complete digestive tract from mouth to anus. Bacteria and waste found in feces serve as food for L1. As larvae continue to develop, the outer cuticle will begin to shed within two days of hatching, and the larvae will molt into L2. Increased motility and feed consumption can be used as an indicator of L2 maturation (Veglia, 1916).

Under desirable warm and moist environmental conditions larvae will continue to develop and molt into L3, the infective stage. Movement and travel occurs most at dawn, as larvae travel up grass blades in dew droplets due to natural cohesion, where ingestion may occur by a grazing host. During the day larvae can be found protected from sunlight, closer to the ground and in feces. Infective L3 have been found to be most active between temperatures of $42^{\circ}-50^{\circ} \mathrm{C}$ (Veglia, 1916). Structurally, L3 are encased in a cuticle which protects them from the environment, desiccation, and covers their mouth, preventing the larvae from feeding. At this point larval metabolism is dependent on the consumption from both the L1 and L2 stages (Veglia, 1916).

Infective L3 are ingested by a grazing sheep, and travel through the host's digestive tract and begin exsheathment and development to L4 within the abomasum 48 hours after ingestion. In the abomasum, L4 pierce the mucosal lining and feed off pools of blood (Roberts and Janovy, 2005). L4 stage within the abomasum can undergo an arrested stage in times of unfavorable 
external environmental conditions for parasite development called hypobiosis (Gibbs, 1986). Three days after ingestion, larvae molt from L4 and become mature adults worms. Sexually dimorphic adults will reproduce and continue to take blood meals from its host, perpetuating the life cycle (Veglia, 1916).

Lambs younger than 6 months of age and immunocompromised individuals are most affected, with peak infection typically occurring throughout spring and summer months (Dineen and Wagland, 1966). While in the host, during winter months, larvae deposited during summer months go into hypobiosis until the external environment is suitable for maturation (Donald, 1978). There is a positive correlation between the number of adult $H$. contortus worms found in the abomasum of infected sheep, and the number of eggs that are shed in the feces (Roberts, 1981). Producers utilize fecal egg counts (FEC) as an approximation of parasite burden or as a useful indicator of anthelmintic treatment effectiveness expressed as the number of eggs per gram of feces (EPG). Packed cell volume (PCV), a marker of anemia, is also utilized as a measure of infection (Clark et al., 1962). The prevalence of infection with $H$. contortus follows a trend of the availability of L3 on pasture (Donald, 1978).

Pathologies associated with Haemonchosis range from sub-clinical to lethal pathologies and are a result of blood feeding by L4 and adult stages (Browning, 2006). Symptoms of acute disease depend on infection intensity and include weakness, anemia, reduced wool production and muscle mass or even sudden death (Veglia, 1916). Chronic disease pathologies of H. contortus infection include decreased food intake, weight loss, anemia, and death (Pugh et al., 2012). Parasitic infection can also have indirect effects on metabolism, forcing its host to utilize protein stores during an immune response and lead to decreased feed intake and increased susceptibility to other pathogens (Moreau, 2010). 


\section{$\underline{\text { Management of Haemonchosis }}$}

Initial reports of $H$. contortus anthelmintic resistance in sheep occurred in the late 1950's to the drug phenothiazine (Drudge et al., 1957). Field populations of $H$. contortus have shown resistance to all major anthelmintic drug classes including benzimidazoles, imidazothiazoles, and macrocyclic lactones. Resistance appeared less than 10 years after the introduction of a new drug class (Kotze and Prichard, 2016). Thiabendazole was introduced in 1961 as the first to combine broad-spectrum nematocide with low toxicity. Within a few years, resistance was reported in sheep operations due to anthelmintic overuse. Similar trends in resistance patterns have been reported for benzimidazoles and imidazothiazole drug classes within a few years of efficacy (Conway et al., 1964; Waller et al., 1986). Resistance to the most recent drug treatment available in Australia, amino-acetonitrile derivatives (AADs), has recently been reported in $H$. contortus (Mederos et al., 2014; Van den Brom et al., 2015). As the level of resistance continues to increase, the efficacy for drugs will continue to decline, leaving producers with the choice to utilize alternative methods to managing parasitism.

Incorporating parasite-resistant breeds of sheep into breeding programs has been an alternate strategy of interest for controlling $H$. contortus infection. Resistant sheep do not completely eradicate the infection, but they have a lower parasitic load, as measured by fewer eggs in their feces, and a decrease in abomasal worm burden at necropsy as compared to susceptible sheep (Gill, 1991). Due to natural selection, Caribbean native St. Croix (STC) sheep are able to thrive in temperate, high parasitic environments (Shakya et al., 2009). St. Croix sheep are of Caribbean origin, which is an environment conducive to year-round exposure to $H$. contortus. St. Croix have developed a robust immune response early to larval stages of $H$. contortus preventing establishment of adults (Alba-Hurtado and Munoz-Guzman, 2013). However, parasite-resistant St. 
Croix sheep lack economically desired traits; reducing their usefulness in a crossbreeding program (Gamble and Zajac, 1992). Suffolk (SUF) sheep, originating in cold and wet environments of England, are a common economically desirable breed that are highly susceptible to $H$. contortus (Miller et al., 1998). Inability of SUF to respond to larvae permits the establishment of adults within the abomasum, leading to adverse symptoms such as anemia, edema, hypoproteinemia, weight loss, and in severe cases, death (Miller et al., 1998). Symptoms are most prevalent in young animals, while recurrent exposure to infection aids in resistance development in adult animals (Barger et al., 1985).

Resistance to $H$. contortus is immunologically mediated. Treatment of Gulf Coast Native resistant sheep with dexamethasone for immune suppression led to a reduction in resistance profile, characterized by higher eggs per gram and increased total worm burden within the abomasum of resistant hosts (Peña et al., 2004). Pasture infected St. Croix lambs have demonstrated the ability to respond to $H$. contortus larval stages early in infection as shown by eosinophilia, mast cell hyperplasia, and globule leukocytosis within the abomasal mucosa (Shakya et al., 2009). Studies have observed delayed responses of immune components vital for T-helper 2 (Th2) initiation in SUF. For instance, gene expression analysis of wound healing and tissue repair associated genes were upregulated in abomasa tissue of STC lambs and downregulated in SUF lambs after $H$. contortus infection (MacKinnon et al., 2015).

\section{$\underline{\text { Immune response to Helminths }}$}

According to the world health organization (WHO), more than two billion humans are infected with parasitic helminths. Although infections by these pathogens are not always fatal, they have been associated with high rates of morbidity, anemia, malnourishment, and coinfection (WHO, 1999). Helminth diseases are still widespread affecting all mammals and drug treatments 
have declined in effectiveness due to overuse. Mechanisms of resistance to helminths are not yet fully understood. Thus far there has been discovery of innate and adaptive responses necessary for proper eradication of helminths from their host (Patel et al., 2009). The host protective immune response has been referred to as Th2 immune activation. Host Th2 activation to helminth larval stages reduce adult establishment and fecundity, further reducing symptoms and pathologies associated with helminth disease (Owyang et al., 2006).

T-helper type 2 responses are characterized by an increase in IL-4, IL-13, IL-5, IL-21, and IL-25 cytokines, which promote the recruitment, activation, and expansion of cluster of differentiation (CD) $4^{+} \mathrm{Th} 2$ cells, plasma secreting IgE and IgA cells, eosinophils, mast cells, and basophils (Balic et al., 2000; Lacroux et al., 2006). The life cycle of Nippostrongylus brasiliensis (N. brasiliensis) in rodents follow a pattern of hepato-tracheal migration, and serves as a useful model to study host immunopathology arising from nematode infections (Ehigiator et al., 2000). N. brasiliensis immune mechanism is $\mathrm{CD}^{+} \mathrm{T}$ cell mediated with the dependence on IL-4 production to induce B cell class switching and promote increased IgE in host serum within 7-13 DPI (LeGros et al., 1996). Basophils have been implicated to be the effector source of IL-4 production during primary $N$. brasiliensis infection independent of both IL-4/STAT6 signaling. During challenge infection, basophils are rapidly recruited however, $\mathrm{CD} 4^{+} \mathrm{T}$ cells serve as the dominant source of IL-4. Basophils, during N. brasiliensis infection, are not necessary for Th2 differentiation, as the number of B cells present in the local lymph nodes were not affected when basophils were depleted. However, effector cell recruitment to the periphery is affected by basophil depletion (Van Panhuys et al., 2011).

Studies have shown an increase in IL-5 induced in blood and in the lungs within 7-9 DPI, promoting eosinophilia (Coffman et al., 1989; Kopf et al., 1993). The final phase of infection is 
characterized by an increase in IL-4, IL-13, and IL-9 dependent mastocytosis followed by an influx of IL-13 and IL-4 within the mucosal wall of the gut, aiding in parasite expulsion from the small intestine (Madden et al., 1991; Townsend et al., 2000; Urban et al., 1998).

Heligmosomoides polygyrus ( $H$. polygyrus) biology in mice has been used as a natural model of nematode infection because its mode of infection resembles that of $H$. contortus and it can be examined from several aspects of the host parasite interface. Resistance to $H$. polygyrus infection is immune mediated and $\mathrm{CD}^{+} \mathrm{T}$ cell dependent (Urban et al., 1991a). The level of infection within a rodent host has shown to be limited by the expression of IL-4 at the site of infection (Urban et al., 1991b), which is dependent on IL-4Ra receptor activation of STAT6 (Finkelman et al., 1997). Host resistance is composed of both a primary and secondary response. Primary responses include modest changes in intestinal epithelial cell function, including permeability and early innate cell influx associated with IL-4 production (Shea-Donohoue et al., 2001). Memory responses have been shown to occur within 4 DPI, characterized by granulomatous formation consisting of neutrophil infiltration surrounding invading larvae, followed by alternatively activated macrophages (AAM $\phi$ ) surrounding larval and neutrophils clumps (Anthony et al., 2006; Morimoto et al., 2004; Kreider et al., 2007). Granuloma formation is indicative of acute inflammatory responses to invading pathogens necessary for full host protective immunity (Gause et al., 2003). At the border of the granuloma there is an accumulation of $\mathrm{CD} 4^{+} \mathrm{T}$ cells, dendritic cells, and eosinophils (Anthony et al., 2006). The memory response in H. polygyrus infection is heightened by the dichotomy of an acute inflammatory response and a memory Th2 response leading to immune cell influx to the site of infection, resulting in parasite damage (Anthony et al., 2006). 


\section{$\underline{\text { Neutrophils }}$}

Neutrophils are short-lived, terminally differentiated, innate immune cells that play a primary role in the resistance against extracellular pathogens and acute inflammation, through trapping with neutrophil extracellular traps (NETs), reactive oxygen species production, cytokine production, and engulfing if the pathogen is small enough (Borregaard et al., 2010). Interleukin17 and related cytokines are known mediators of granulopoiesis and neutrophil proliferation (Cua et al., 2010). Neutrophils are the most abundant white blood cell found in human circulation Nathan et al., 2006). Recruitment of neutrophil to infection sites has been shown to be dependent on cytokines such as, IL-17, IL-8, CXCL1, interferon- $\gamma($ IFN $\gamma)$, tumor necrosis factor (TNF), and granulocyte-macrophage colony-stimulating factor (GM-CSF) (Pelletier et al., 2010). Neutrophils ability to adapt to the their environment and alter phenotype has been under investigation, specifically in neutrophils ability to switch from a classical-Th17 (N1) phenotype necessary for inflammatory responses to an alternative (N2) phenotype, found in anti-inflammatory/helminth responses. Fridlender et al., (2009) were first to introduce the concept of N1/N2 polarization within an anti-tumor microenvironment. Classic inflammatory N1 neutrophils support an anti-tumor environment while $\mathrm{N} 2$ populations suppress inflammatory responses leading to a pro-tumor environment. Following a myocardial infarction, N2 populations were shown to contribute to resolution and tissue repair, by decreasing inflammatory responses and aiding in damage repair (Ma Y et al., 2016). Polarized neutrophil populations have also been observed in the context of a helminth parasitic infection.

During Nippostrongylus brasiliensis infection in mice, neutrophils were shown to adopt a distinct transcriptional profile (N2), characterized by upregulated expression of Th2 associated genes (Arginase-1 (Arg1) and IL-13) (Chen et al., 2014). Polarized neutrophils (N2) were able to 
promote the recruitment and activation of alternatively activated macrophages (AAM $\phi)$ with the production of both monocyte chemoattractant protein 1 (MCP1) and IL-13 during a helminth infection, resulting in an accumulation of $\mathrm{AAM} \phi$ at the site of infection and downregulation of type 1 inflammatory responses (Noel et al., 2004). Murine N2 were able to activate AAM $\phi$ via IL13 production, this led to $\mathrm{AAM} \phi$ being better equipped for larval killing in vitro, characterized by a reduction in larval ATP and reduced larval establishment within the gut of murine hosts (Chen et al., 2014).

\section{$\underline{\text { Interleukin-4 (IL-4) }}$}

Interleukin-4 is a multifunctional cytokine that signals using the IL-4R complex and plays a critical role in the regulation of immune responses. This molecule exerts various biological effects by regulating proliferation and differentiation of a variety of lymphoid and myeloid derived cells (Paul et al., 1991). Previous studies suggest that human peripheral monocytes, IL-4/IL-13 production significantly downregulate expression of classically proinflammatory cytokines such as IL-1, IL-6, IL-8, IL-18, and TNF $\alpha$ in human peripheral monocytes (Chaitidis et al., 2005). Interleukin-4 activation can recruit mediators of cell growth, resistance to apoptosis, and gene activation and differentiation. The development of Th2 cytokine-deficient mice provided an opportunity to investigate complex interactions between IL-4, IL-5, IL-9, and IL-13. Thelper- type 2 cytokines, together, add to the rate and magnitude of the response to a pathogen, however, IL-4 alone has been shown to activate all Th2 effector functions (Fallon et al., 2002). A multitude of innate cells have been shown to be a source of IL-4 such as eosinophils, basophils, nuocytes, and mast cells (Seder et al., 1994; Van Panhuys et al., 2011). Innate cells early recruitment to the site of infection can deem them a source of early IL-4, which is necessary for Th2 differentiation indicative of parasite expulsion. Memory T-helper $\left(\mathrm{CD}^{+}\right) \mathrm{T}$ cells, during challenge infection, has 
been implicated as a sole source of IL-4 during helminth infection (Seder et al., 1994). Interleukin4 stimulation initiates $\mathrm{CD} 4^{+} \mathrm{T}$ cell differentiation, which activates a cascade of the release of $\mathrm{Th} 2$ associated cytokines (Seder et al., 1992; Hsieh et al., 1992). Expression of IL-4 has been associated with decreases in IFN $\gamma$ producing $\mathrm{CD}^{+}{ }^{+} \mathrm{T}$ cells (Coffman et al., 1986), promoting B cell class switching to express IgE, IgG, and IgA (Vitetta et al., 1985), and has also been associated with the increased expression of major histocompatibility complex II (MHC II) in B cells (Noelle et al., 1984).

\section{$\underline{\text { Interleukin-13 (IL-13) }}$}

Interleukin-13 was originally described as a $\mathrm{T}$ cell derived cytokine that had the ability to inhibit inflammatory cytokine production (Minty et al., 1993). Recent studies have associated IL13 with roles such as, B cell class switching to IgE and upregulation of Th2 associated genes in monocytes (Minty et al., 1993). The discovery of IL-13 knockout mice have allowed for the further elucidation of the role of IL-13 during helminth infection (McKenzie et al., 1999). IL-4 and IL-13 are functionally related however, in some situations, IL-13 has been shown to be of greater importance than IL-4, in the context of helminth infection. Availability of both molecules and the receptor combination expressed on the available cell dictates the overall importance of IL-4/IL-13 (Madden et al., 1991). During $N$. brasiliensis infection, IL-13 was shown to stimulate parasite expulsion in immunodeficient recombination-activating gene 2 (RAG) $2^{-/-}$mice as shown by a reduction in parasite burden, suggesting IL-13 mediates parasite expulsion by directly activating an unknown nonlymphoid cell within the gut (Barner et al., 1998). 
Interleukin-13 has been characterized as an IL-4-like cytokine with similar roles in parasite resistance and altering the gut environment (Madden et al., 1991). Increased fluid in the intestinal lumen has been identified as a vital component to the host response to enteric infections facilitating parasite expulsion (Cooke, 1998). Interleukin-4 and IL-13 share a receptor subunit and together have shown the ability to change epithelial cell resistance, absorption, and secretion, and these changes were Signal transducer and activation of transcription factor 6 (Stat6) dependent (Madden et al., 2002).

High Affinity Interleukin-4 Receptor Subunit $\alpha$ (IL-4R $\alpha)$

T helper type 2 activation during helminth infection has shown dependence on IL-4 and IL-13 signaling, both molecules signal through IL-4R $\alpha$. Gut nematode infections have deemed IL4R $\alpha$ signaling to be critical in the initiation and development of host protective Th2 responses during both primary and secondary infections (McKenzie et al., 1999; Anthony et al., 2006). Recent studies have investigated importance of IL-4R $\alpha$ during $N$. brasiliensis infection, with use of a Cre-Lox recombination to disrupt IL-4R $\alpha$ signaling (Horsnell et al., 2010). Impairment of IL4R $\alpha$ signaling during primary and secondary infection led to disruption in Th2 responses and affected the host's ability to expel the worms. To observe the efficacy of long lasting IL-4R $\alpha$ expression, mice were treated with tamoxifen, to block IL-4R $\alpha$ signaling, after the clearance of a primary infection and then re-infected to analyze memory responses in the absence of IL-4R $\alpha$ expression. Mice treated with tamoxifen displayed a susceptible phenotype characterized by increased adult worm and larval burden, while the control mice with intact IL-4R $\alpha$, treated under the same conditions, displayed a resistant profile (Nono et al., 2017). These studies implicate the importance of IL-4R $\alpha$ expression in eliciting a proper host protective Th2 response. 


\section{$\underline{\text { Signal Transducer Activating Transcription } 6 \text { (STAT6) }}$}

Signal transducer and activation of transcription factor 6 (STAT6) is a member of the STAT family of transcription factors. Activation of STAT6 signaling is initiated by the binding of the cytokine ligands IL-4 or IL-13 to the shared cell surface receptor complex IL-4R $\alpha$. Ligation of the surface receptor activates Janus Kinase 2 (JAK2), which phosphorylates proteins. Janus kinase 2 utilizes adenosine tri-phosphate (ATP) to phosphorylate tyrosine residues on the intracytoplasmic region of IL-4R, thus turning on the pathway. Commonly, STAT6 molecules are found in the cytoplasm. Upon activation of JAK2, STAT6 molecules will attach to the phosphorylated tyrosine residue, allowing JAK2 to phosphorylate STAT6 proteins. Phosphorylation of STAT6 molecules promotes dimerization of STAT6 molecules and allow complex to be translocated to the nucleus. The STAT6 complex will then bind to promoter regions of DNA and activate translation of specific sequences on the DNA. This process promotes production of Th2 cytokines, leading to activation Th2 responses (Oshea, 1997). Use of STAT6deficient mice has revealed the importance of STAT6 signaling in Th2 differentiation. The STAT6-deficient mice failed to elicit $\mathrm{T}$ cell differentiation as observed by the lack of IL-4 responses and the inability of B cells to produce IgE (Kaplan et al., 1996). The use of STAT6 pharmacological inhibitors in experiments has been vital in therapeutic discoveries and elucidation of Th2 immune mechanisms (Nagashima et al., 2006).

\section{$\underline{\text { Immune response to Haemonchus contortus }}$}

Th2 immune activation, in response to $H$. contortus larval stages, reduce adult establishment and fecundity. Innate immune cell influx (eosinophils, mast cells, globule leukocytes), cytokine production (IL-4, IL-5, IL-13), and increased parasite-specific antibody 
(IgA, IgE) production are all implicated in parasite expulsion (Balic et al., 2000, Lacroux et al., 2006). The gastrointestinal environment during a Th2 response is characterized by increased luminal flow coupled with intestinal muscle contractility, and these responses are driven by IL-4 and IL-13 cytokines (Harris et al., 2011).

In the context of $H$. contortus infection in sheep we have demonstrated a correlation between elevated IL-4 and IL-13 expression during early infection and prevention of parasite establishment. Initial IL-4 expression was detected in STC abomasal tissue by day 3 and in SUF sheep at day 10-post infection. These data indicate a delay in IL-4 expression in susceptible sheep (Jacobs et al., 2016). IL-13 expression at 3 days post infection (DPI) was significantly increased in both STC abomasum and lymph node tissue but was markedly reduced in susceptible sheep (MacKinnon et al., 2015). Delayed SUF IL-4 expression and reduced IL-13 expression to Haemonchus larval stages in susceptible hosts, permit the establishment of adults. Despite evidence for IL-4 and IL-13 being critical in generating Th2 responses, the early source of these cytokines has not been fully elucidated.

Bowdridge et al., (2015) identified cellular infiltrate of abomasal tissue during the first 7 days of $H$. contortus infection and found a significant increase of neutrophil in STC abomasum when compared to SUF sheep at 3 DPI. From recent data, it is reasonable to conclude early neutrophil infiltration, IL-4 production, and increased early IL-4 and IL-13 expression in abomasal tissue of STC lambs drive AAM $\phi$ polarization. The interaction between neutrophil cytokine production and the activation state of $\mathrm{AAM} \phi$ remain unknown in a sheep Haemonchus contortus infection model.

Similar responses have been observed in ovine gastrointestinal nematode in vitro models, $H$. contortus infected STC PBMC (composed of monocytes and lymphocytes) cultured with larvae 
led to a reduction in larval motility (Holt et al., 2015). Quantifying larval death after culture with PBMC by ATP quantification further found a greater reduction in larval ATP when cultured with STC PBMC than SUF PBMC (Shepherd et al., 2017).

Taken together, these studies demonstrate the significance of early IL-4/IL-13 signaling in promoting parasite expulsion. The effector cell responsible for the production of early IL-4 aiding the differentiation of naïve T cells to Th2 cells has yet to be identified. Interleukin- 4 acting on Th2 cells causes the subsequent production of IL-4 creating a positive feedback loop and promoting the differentiation of $\mathrm{B}$ cells to plasma cells, necessary for both $\operatorname{IgE}$ and $\operatorname{IgG}$ production. Differences between resistant and susceptible sheep have been documented with emphasis on a delay in response to larval stages observed by susceptible sheep. Upon characterizing cellular infiltrates at the infection site at day 3 , neutrophils have shown to be the only innate cell to have a significant difference in abomasal tissue between resistant and susceptible breeds. The experiments contained herein serve to elucidate the role of cytokines produced by neutrophils on the activation state of other immune cells to elicit Th2 responses necessary for protection against parasitic infection. Understanding differences observed in early responses to larval stages could aid in future therapies to assist commercially favorable breeds in their response to $H$. contortus GIN infection. 


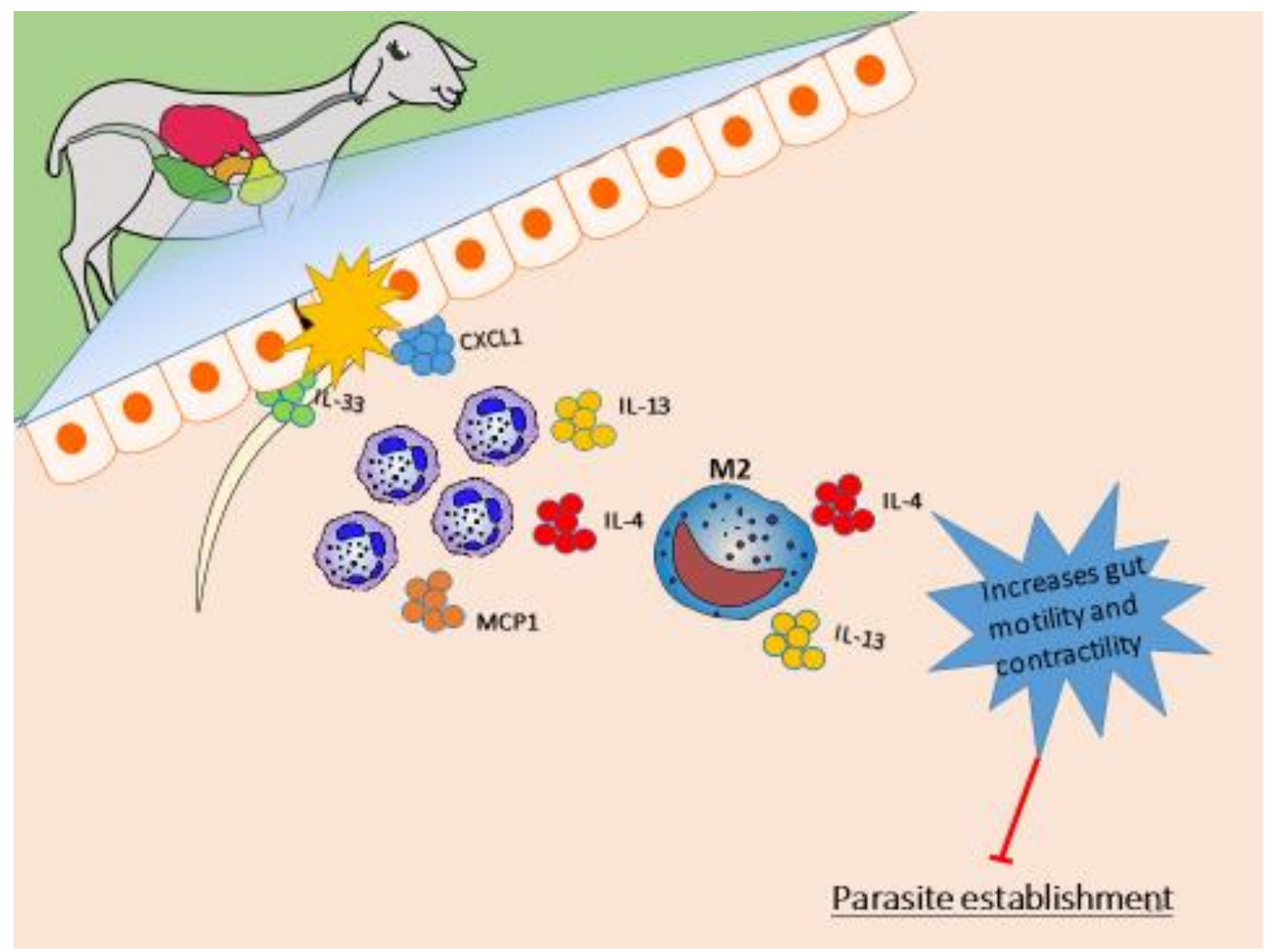

Figure 1: Model of resistance to $H$. contortus infection in sheep

Resistant breeds are able to respond early in infection to larval stages upon disruption of epithelial cells. Epithelial cell damage leads to the release of chemokines CXCL1 and IL-33, promoting the recruitment of neutrophils to the site of infection. Neutrophils at the site will then produce cytokines such as IL-4, IL-13, and MCP1 leading to the recruitment and differentiation of macrophages to AAM $\phi$. The alternative macrophage phenotype will then produce both IL-4 and IL-13 cytokines, increasing gut motility and contractility. Resulting in the inhibition of parasite establishment. 


\section{Chapter 2: Materials and Methods}

\section{Experimental Design}

St. Croix (STC) $(n=5)$ and Suffolk (SUF) sheep $(n=5)$ were raised under parasite-free conditions at the West Virginia University Animal Science Farm to allow for controlled and monitored infection. For each experiment 3 out of 5 animals per breed were used for whole blood collection for cellular isolation. Animals in this study were not exposed to H. contortus infection prior to experimental inoculation. Four weeks after weaning, primed animals received a single oral dose of 10,000 H. contortus infective stage larvae (L3). Infection persisted for six weeks before animals were dewormed using levamisole $(8 \mathrm{mg} / \mathrm{kg})$ and rested for three weeks. Following the rest period, lambs were challenged with an additional dose of 10,000 L3. Fecal egg count (FEC) and packed cell volume (PCV) were performed weekly throughout primary and challenge infection to monitor infection. At the time of experimentation lambs were primed, but not under active infection.

\section{Haemonchus contortus larval culture}

Feces were collected from $H$. contortus-infected SUF wethers, used solely for the purpose of growing and collecting infective stage larvae. Feces were mixed with sterilized peat moss and activated charcoal and incubated for 7 days at $30^{\circ} \mathrm{C}$. Larvae were isolated using a Baermann apparatus (Zajac and Conboy, 2006) and stored in phosphate buffered saline (PBS) (pH 7.4) at $4^{\circ}$ $\mathrm{C}$ for no longer than 3 months before use. Larvae were diluted to a concentration of $1000 \mathrm{~L} 3 / \mathrm{mL}$ in sterile PBS before use. 


\section{Parasitic antigen}

Crude larval antigen (HcLA)

Infective stage L3 were removed from feces and placed in PBS (pH 7.4) and homogenized on ice using a Dounce homogenizor. Lysate was centrifuged at $15,000 \mathrm{x} \mathrm{g}$ at $4^{\circ} \mathrm{C}$ for $1 \mathrm{~h}$. Supernatant was removed and passed through a $0.22 \mu \mathrm{m}$ syringe filter for sterilization. Protein concentration was determined using micro-BCA assay (Pierce, Rockford, IL). Protease inhibitor cocktail (Sigma Aldrich, St. Louis, MO) was added at $1 \mu 1$ of cocktail per $\mu g$ of protein. Crude larval antigen was aliquoted into $1.5 \mathrm{ml}$ centrifuge tubes and stored at $-80^{\circ} \mathrm{C}$ until further use.

\section{Crude worm antigen (HcWA)}

Adult $H$. contortus worms were extracted from the abomasum of euthanized sheep and placed in chilled PBS ( $\mathrm{pH}$ 7.4). The worms, in PBS, were homogenized using a dounce homogenizer on ice. Lysate centrifuged at $15,000 \mathrm{x} \mathrm{g}$ at $4^{\circ} \mathrm{C}$ for $1 \mathrm{~h}$. Supernatant was removed and run through a $0.22 \mu \mathrm{m}$ syringe filter for sterilization. Protein concentration was determined using miro-BCA assay (Pierce, Rockford, IL). Protease inhibitor cocktail (Sigma Aldrich, St. Louis, MO) was added at $1 \mu \mathrm{l}$ of cocktail per $\mu \mathrm{g}$ of protein. Crude worm antigen was aliquoted into $1.5 \mathrm{ml}$ centrifuge tubes and stored at $-80^{\circ} \mathrm{C}$ until further use.

\section{Immune cell isolation from whole blood}

\section{Neutrophils}

Whole blood samples ( $\mathrm{n}=5$ tubes/breed) were collected via jugular venipuncture into 10 ml vacutainer tubes containing ethylenediaminetetraacetic (EDTA) (Patterson vet, Saint Paul, $\mathrm{MN})$. Blood tubes were pooled into a single sterile $50 \mathrm{ml}$ centrifuge tube for centrifugation at 400 $\mathrm{x} g$ for 20 minutes at RT. Plasma layer and buffy coat was removed and red blood cells (RBC) were lysed by adding $150 \mathrm{ml}$ of sterile water and mixing for 20 seconds followed by immediate addition of $9 \%$ sterile saline bring solution to an isotonicity. Isotonic solution was centrifuged at 
$250 \mathrm{x} g$ for 5 minutes at RT. Resulting pellet was resuspended in $1 \mathrm{ml}$ of PBS (pH 7.4) and layered over a $65 \%$ percoll (Sigma-Aldrich, St. Louis, MO) gradient and centrifuged at $400 \mathrm{x} g$ for $20 \mathrm{~min}$ at RT. Cellular pellets were washed with PBS then suspended in complete media (CM) containing RPMI-1640 with 2mM L-glutamine, 10\% fetal bovine serum (FBS) and penicillin-streptomycin antibiotic. Neutrophils were counted using a hemocytometer (Thermo Scientific, Waltham, MA).

\section{Peripheral blood mononuclear cell (PBMC)}

Whole blood samples were collected via jugular venipuncture into ( $\mathrm{n}=5$ tubes/breed) 10 ml EDTA treated vacutainer tubes (Patterson vet, Saint Paul, MN). Peripheral blood mononuclear cell isolation was performed by centrifugation of blood samples at $1,000 \mathrm{x} g$ for $20 \mathrm{~min}$ at RT. Buffy coats were collected into a 15-ml sterile centrifuge tube suspended in 1-ml of sterile PBS (pH 7.4). Red blood cells were removed using ACK lysis buffer (Lonza, Walkersville, MD), and the resulting pellet was layered over sterile lymphocyte separation media (LSM) (Fisher Scientific, Hampton, NH) and centrifuged at $400 \times \mathrm{g}$ for 20 minutes at RT. Peripheral blood mononuclear cells were isolated and counted using TC-20 automated cell counter (Bio-RAD, Hercules, CA). Cells were diluted to a concentration of $1 \times 10^{6}$ cells $/ \mathrm{ml}$ for use in culture and suspended in CM.

\section{Cytokine ELISA}

Concentration of IL-4 and IL-13 protein were detected in culture supernatant using ovine specific ELISA kits (MyBioSource, San Diego, CA, USA) after antigen stimulation for 0.5, 1, 3, $6,12,24$ hrs according to manufacturer's protocol. Treatment groups were diluted at 1:10 and tested in triplicate. Samples were read at $450 \mathrm{~nm}$ and a standard curve was generated to detect IL$4(6.25$ to $400 \mathrm{pg} / \mathrm{mL}$ range). Samples were read at $450 \mathrm{~nm}$ and a standard curve was generated to detect IL-13 (7.81 to $500 \mathrm{pg} / \mathrm{ml})$. 


\section{RNA and cDNA preparation}

Total RNA was isolated from neutrophils after $0.5,1,3,6,12,24$ hours of antigen stimulation using Direct-zol RNA MiniPrep Plus (Zymo Research, Irvine, CA). Briefly, cells were lysed in $300 \mu 1$ of TRI reagent. Lysate was filtered through a Zymo-spin column, DNA was digested using DNase. RNA was washed and dried on a silica membrane, then eluted into RNasefree water. Samples were read on a BioTek plate reader measuring concentration and 260:280 for quality (BioTek, Winooski, Vermont). Synthesis of cDNA was prepared using a High Capacity cDNA Reverse Transcription Kit (Thermo Fisher Scientific, Waltham, MA). Reactions were prepared by combining $10 \mu 1$ of $2 \mathrm{X}$ RT master mix and $10 \mu \mathrm{l}$ RNA sample, then placed in T100 thermal cycler (Bio-Rad, Hercules, CA). Thermocycler conditions were 10 min of heating at $25^{\circ}$ $\mathrm{C}$, then to $37^{\circ} \mathrm{C}$ for $120 \mathrm{~min}$, and $85^{\circ} \mathrm{C}$ for $5 \mathrm{~min}$ for 40 cycles, and lastly cooled to $4^{\circ} \mathrm{C}$. (BioRad, Hercules, CA).

\section{Gene Expression Analysis}

\section{$\underline{\text { Taqman Assays }}$}

For qPCR, samples were made up of $10 \mu 12 \mathrm{X}$ TaqMan Gene Expression Master Mix (Applied Biosystems, Foster City, CA), $2 \mu 1$ (100ng) cDNA template, $1 \mu 1$ of IL-4 (assay ID: Oa04927178_s1), Major histocompatibility complex II (MHC II) (assay ID: Oa04925564_s1) or GAPDH (assay ID: Bt03210913_g1), 20x Taqman probes (Applied Biosystems, Foster City, CA) and $7 \mu 1$ RNase-free water. Samples were analyzed in quadruplicate using CFX96 system (BioRad, Hercules, CA). Conditions of qPCR were performed using the following thermal-cycler profile: 10 minute hold at $95^{\circ} \mathrm{C}$, then 40 cycles of 15 seconds at $95^{\circ} \mathrm{C}$ denaturation and 20 seconds at $60^{\circ} \mathrm{C}$ extension. The reference gene used for normalization was GAPDH. Missing time points in recorded values were undetectable. 


\section{$\underline{\text { SYBR Green Assays }}$}

The qPCR reactions were run in triplicate with a Bio-Rad CFX96 system. Reaction conditions were: $50^{\circ} \mathrm{C}$ for 10 minutes and an initial denaturation at $95^{\circ} \mathrm{C}$ for 5 minutes followed by 40 cycles of denaturation at $95^{\circ} \mathrm{C}$ for 10 seconds and extension for 30 seconds at $60^{\circ} \mathrm{C}$. The PCR amplifications were carried out in a total volume of $20 \mu 1$, containing $10 \mu \mathrm{L}$ SYBR Select Master Mix (Life Technologies, Burlington, ONT Canada), 1.2 $\mu \mathrm{L}$ of each forward and reverse primers, $2 \mu \mathrm{L} 100 \mathrm{ng} / \mu \mathrm{L}$ cDNA template, and $5.6 \mu \mathrm{L}$ DECP-treated water.

The relative fold change in gene expression of candidate genes was done using the 2- $\Delta \Delta \mathrm{Ct}$ method (Livak and Schmittgen, 2001). The obtained Ct values are used to calculate $\Delta \mathrm{Ct}$ values of genes of interest [Ct (test) - $\mathrm{Ct}$ (reference)]. The reference gene used for normalization was GADPH. Graphical representation for each gene was based on fold change over CM control treated groups. Missing time points in recorded values were undetectable.

\section{Alamar Blue Proliferation Assay}

In preparation of culture neutrophils were plated in a 96-well plate at 100,000 cells per well and cultured with HcLA $(20 \mu \mathrm{g} / \mathrm{ml})$ or CM (each group run in replicate) and incubated for 3 hours at $37^{\circ} \mathrm{C}$ and $5 \% \mathrm{CO}_{2}$. After priming, neutrophils were washed with PBS and cocultured with PBMCs at a concentration of 100,000 cells per well and cocultured for 72 hours. After culture, proliferation was quantified by use of alamar blue assay (Thermo Fisher Scientific, Waltham, MA) with the absorbance reading at $570 \mathrm{~nm}$ and using $600 \mathrm{~nm}$ as a reference wavelength.

\section{Statistical Analysis}

Statistical analyses for protein analysis and proliferation assays were analyzed using Sigma Plot software. A two-way ANOVA with fixed effects of breed and treatment was used to assess 
proliferation experiments. Fisher LSD was used for means comparison. For protein analysis, a three-way ANOVA with fixed effects of breed, treatment, and time were used and the Holm-sidak post hoc test was utilized for means comparison. Differences were considered significant if $\mathrm{P}<$ 0.05 for all experiments. Statistical analysis for qPCR data was based on fold change values, results were normalized to both CM control group and GAPDH and reported as fold change. Data were analyzed using the General Linear Model (GLM) in Statistical Analysis System (SAS) with fixed effects of breed, treatment, and time. All two and three-way interactions were analyzed. Bonferroni test was used for means comparisons of the main effects. Means comparisons of interactions were analyzed using LSmeans and differences were detected using Bonferroni's test. Significance was accepted at $\mathrm{P}<0.05$. 


\section{Chapter 3: Results}

\section{Neutrophil IL-4 and IL-13 protein production, in vitro}

To determine differences in IL-4 and IL-13 protein production neutrophils from STC and SUF sheep were isolated from whole blood and stimulated with $20 \mu \mathrm{g} / \mathrm{ml}$ of HcLA or HcWA at various time points before performing an ovine-specific IL-4 and IL-13 ELISA. During the first 3 hours of in vitro stimulation of naïve neutrophils with HcLA, cells from both STC and SUF were able to produce high amounts of IL-4 at $4256.5 \mathrm{pg} / \mathrm{ml}$ (STC) and $4569.8 \mathrm{pg} / \mathrm{ml}$ (SUF) by $30 \mathrm{~min}$ after stimulation. Interleukin-4 production was significantly reduced in all breeds after 3 hours of antigen stimulation. By 24 hrs there was an $80 \%$ reduction in IL-4 production (figure $2 \mathrm{~A}$ ). Minimal amounts of IL-4 protein were detected for both breeds after stimulation with HcWA (figure 2B). When observing the average IL-4 protein production over a $24 \mathrm{hr}$ time course, both breeds produced more IL- 4 in response to larval stimulation, with no differences observed between breeds (figure 2C). Observing the average IL-4 protein production after adult antigen stimulation over time, IL-4 protein levels did not deviate from the complete media control groups (figure 2D). No breed effects were observed in either antigen treatment, yet there was a dramatic difference in IL-4 production that was dependent on antigen coming from different parasitic life stages $(\mathrm{P}<$ 0.0001) (figures $2 \mathrm{~A}$ and $2 \mathrm{~B}$ ).

The pattern of neutrophil IL-13 production was markedly different than what was observed for IL-4. Production of IL-13 in response to HcLA did not occur until 6-hour of antigen exposure. At that time, neutrophils produced IL-13 at $423.92 \mathrm{pg} / \mathrm{ml}$ (SUF) and $450.3 \mathrm{pg} / \mathrm{ml}$ (STC) (figure 3A). After 6 hours, IL-13 production declined to levels similar to what was observed early after antigen exposure (figure 3A). Interestingly, little if any IL-13 production was observed after 
exposure to HcWA (figure 3B). Interleukin-13 protein amounts on average over the $24 \mathrm{hr}$ time course after larval antigen stimulation were not different between breeds, but were greater than IL13 production at basal level (figure 3C). After adult antigen stimulation, IL-13 protein production over time did not exceed basal IL-13 protein amounts (figure 3D). Similar to IL-4, differences were not breed dependent in IL-13 production, IL-13 protein was detected when neutrophils were stimulated with either HcLA or HcWA. But there was a significant amount of IL-13 produced after HcLA stimulation as compared to HcWA stimulation $(\mathrm{P}<0.0001)$.

\section{Neutrophil gene expression after $\boldsymbol{H}$. contortus antigen stimulation}

Gene expression analysis was performed to evaluate breed differences in genes associated with STAT6 signaling; IL-4, IL-13, IL-4R $\alpha$, and STAT6 at 0.5, 1, 3, 6, 12, and 24 hours in response to stimulation with HcLA or HcWA antigen. St. Croix neutrophils were found to have transient expression in IL-4, with a peak at 0.5 and 12 hrs after HcLA stimulation (figure 4A). When stimulated with HcWA STC neutrophils had upregulation of IL-4 expression at all time point's detected (figure 4B). Suffolk neutrophils had similar trends after stimulation with either HcLA or HcWA antigen, peak only at $1 \mathrm{hr}$, the expression was not sustained, occurred early and then downregulated (figures 4C, 4D). St. Croix neutrophils on average, across the $24 \mathrm{hr}$ time course were able to produce greater amounts of IL-4 transcript as compared to SUF neutrophils, after stimulation with either HcLA or HcWA antigen (figures 4E, 4F). Interleukin-13 expression after HcLA expression, for STC neutrophils peaked at $1 \mathrm{hr}$ and was downregulated at all other time points (figure 5A), while SUF neutrophils were found to have upregulation of IL-13 at all-time points (figure 5C). Adult antigen stimulation resulted in transient expression of IL-13 in STC 
neutrophils with peaks in expression at 1 and $12 \mathrm{hrs}$ (figure 5B) and for SUF IL-13 expression was upregulated at all time points detected (figure 5D). Suffolk neutrophils on average, were able to produce more IL-13 transcript than STC neutrophils after stimulation with either HcLA or HcWA antigen over the $24 \mathrm{hr}$ time course (figures 5E, 5F).

Gene expression of the shared receptor subunit for IL-4 and IL-13, IL-4R $\alpha$ was evaluated to observe breed differences. St. Croix neutrophils were found to have downregulation of the receptor at all time points after HcLA stimulation (figure 6A), while SUF had transient expression of the receptor after HcLA stimulation with peaks at 0.5 and $12 \mathrm{hrs}$ (figure 6C). After HcWA stimulation SUF were found to have upregulated expression of IL-4R $\alpha$ at all time points (figure 6D), while STC had transient expression with peaks at 1 and $12 \mathrm{hrs}$ after antigen stimulation (figure 6B). On average, SUF produced more IL-4R $\alpha$ transcript when stimulated with either HcLA or HcWA, when compared to STC (figure 6E, 6F). Signal transducer and activator of transcription 6, the transcription factor necessary for Th2 activation, gene expression was performed to investigate breed differences. Adult antigen stimulation of STC neutrophils resulted in transient expression with peaks at 1 and $12 \mathrm{hrs}$ after antigen stimulation (figure 7B), while HcLA stimulation resulted in a peak at $1 \mathrm{hr}$ and downregulation at all of other time points (figure 7A). Suffolk neutrophils upregulated STAT6 expression at all time points after stimulation with both HcLA and HcWA stimulation with a significant peak in expression at $6 \mathrm{hrs}$ after HcWA expression $(\mathrm{P}<0.0001)$ (figures 7E, 7F). On average, SUF produced greater amounts of STAT6 transcript as compared to STC over the $24 \mathrm{hr}$ time course after stimulation with either HcLA or HcWA (figures 7E, 7F).

Interleukin-17 and its transcription factor STAT3 gene expression were analyzed in ovine neutrophils after $H$. contortus antigen stimulation. The procedure was performed to investigate if neutrophils throughout 0.5 to 24 hours of $H$. contortus antigen processing were undergoing a 
phenotype shift from a pro-Th2 response (N2) to a pro-Th17 (N1) response. St. Croix neutrophils had early expression of STAT3 transcript with a peak at 3 hours before a dramatic decline at 6hours after HcLA stimulation (figure 9A). Stimulation with HcWA had transient expression with upregulation occurring early at 3 hours and later at $12 \mathrm{hrs}$ after HcWA stimulation (figure 9B). Suffolk neutrophil when stimulated with HcLA or HcWA were upregulated at all time points in which expression was detected, peaks in STAT3 expression were found at both 3 and 12 hrs after H. contortus antigen stimulation ( $\mathrm{P}<0.0001)$. On average, across all time point SUF produced more STAT3 transcript as compared to STC after antigen stimulation (figures 9E, 9F). STAT3 is the transcription factor necessary for Th17 associated cytokines, when observing IL-17 expression in $H$. contortus antigen stimulated neutrophils from both STC and SUF sheep transient expression was observed. At 0.5 hour an increase in IL-17 expression occurred until antigen processing took place, which then IL-17 expression downregulated (figures 10A, 10B). After H. contortus antigen was processed neutrophils from both STC and SUF breeds responded with upregulation of IL-17 expression at 24- hours (figures 10A, 10B). On average, across the 24 hour time span STC produced greater IL-17 transcript in response to HcWA stimulation (figure 10D), while SUF on average, produced greater IL-17 transcript in response to HcLA stimulation (figure 10C).

\section{Neutrophil induced PBMC IL-4 production}

Neutrophils were stimulated with HcLA for 3-hours, supernatant was collected and cultured with naïve peripheral blood mononuclear cells (PBMC) for 6-hours. Figure 11A, shows the total amount of IL-4 produced within the treatment groups containing PBMC post neutrophil supernatant stimulation. The amount of IL-4 found within the neutrophil supernatant is quantified in figure 11B. Adjusting for the amount of IL-4 placed in the system, figure $11 \mathrm{C}$ demonstrates the amount of IL-4 protein produced by PBMC alone. An additional experiment was conducted to 
observe cellular communication between neutrophils and other immune cells. Instead of using neutrophil supernatant alone, neutrophils were primed with antigen, washed with PBS, and then cultured with naïve PBMC to investigate IL-4 protein production by PBMC populations. No differences were observed between breeds in IL-4 protein production (figure 12A). After adjusting for the total amount of IL-4 being produced by neutrophils alone, (figure 12B) no breed differences were observed and PBMC showed increased IL-4 protein production after culture with larval antigen primed neutrophils.

Neutrophil transcriptional analysis of the gene MHC II was analyzed over various time points between 0.5 and 24 hours to evaluate neutrophil ability to present exogenous antigen to other immune cells. St. Croix neutrophils had transient expression after stimulation with HcWA; there was a peak in expression observed early at 1 hour and later at 12 hours after stimulation (figure 8B). When stimulated with HcLA STC neutrophils had downregulation of expression (figure 8A). Suffolk neutrophils had a peak in MHC II expression by 3 hours (figure 8C). Larval (HcLA) stimulation of SUF neutrophils had a delay with their peak expression occurring at 6 hours (figure 8C). When comparing STC neutrophil MHC II expression to SUF MHC II expression averaged over the time course, SUF had a significantly higher MHC II expression than STC after stimulation with both HcLA and HcWA (P < 0.0001) (figures 8E, 8F). A proliferation assay was performed to assess PBMC responsiveness to culture with larval antigen primed neutrophils. There were no differences observed between breeds when observing PBMC proliferation, SUF had a slight increase (figure 13). 


\section{Chapter 4: Discussion}

These experiments are first to identify the ability of ovine neutrophils to produce both IL4 and IL-13 in response to $H$. contortus antigen stimulation in vitro. The ability of human neutrophils to produce IL-4 in response to various stimuli has been documented in the literature. Intracellular flow cytometric analysis revealed the presence of intracellular IL-4 in normal human donor neutrophils after stimulation with calcium ionophores (Reglier et al., 1998). Similarly, human neutrophils were stimulated with the promastigote form of Leishmania major for an hour, and qPCR analysis revealed a significant upregulation in neutrophil IL-4 transcript as compared to unstimulated neutrophils (Keyhani et al., 2014). Our data observed similar trends in IL-4 expression with upregulation occurring within an hour after $H$. contortus antigen stimulation. Futhermore, ovine neutrophils were able to produce IL-4 as early as 3 hours of antigen stimulation at a quantity sufficient to activate PBMC which produce additional amounts of IL-4, this leads to a robust type 2 response in the host.

Our data also showed a peak in IL-13 protein production as early as 6-hours after antigen stimulation in both SUF and STC neutrophils. St. Croix neutrophils were able to produce IL-13 transcript within an hour after $H$. contortus antigen stimulation as compared to SUF neutrophils, which took 6-hours to observe a peak in transcript production. Neutrophil's ability to produce IL13 has been studied in the context of Nippostrongylus brasiliensis infection in mice. Murine neutrophils recruited to sites of helminth infection were shown to alter their phenotype through transcriptional analysis and promote differentiation of macrophages into alternatively activated macrophages (AAM $\phi)$ (Chen et al., 2014). Alternatively activated neutrophils (N2) were shown to produce IL-13, which directly acted on macrophages and promoted alternative differentiation. Depletion of neutrophils within the host led to a decrease in macrophage adherence to the parasitic 
larvae (Chen et al., 2014). Further, providing evidence of neutrophils role in both cytokine production and phenotype shift to promote the establishment of type 2 immune responses in reaction to parasite infections. Based on the existing literature, it is reasonable to conclude that early production of IL-4 and IL-13 has the capacity to promote alternative macrophage differentiation early in $H$. contortus infection, thereby promoting parasite expulsion. The presence of $\operatorname{AAM} \phi$ leads to greater production of IL-13, resulting in an increase in epithelial function, greater luminal flow, and gut contractility culminating in parasite expulsion. However, due to the limited evidence to confirm the existence of AAM $\phi$ in sheep (Kreider et al., 2007), further studies are needed to confirm this hypothesis.

Neutrophil plasticity is a phenomenon that similarly requires further investigation. As first responders, neutrophils have an ability to adapt to their environment in order to respond accordingly. During helminth infection, neutrophils respond in a Th2 manner characterized by the production of cytokines such as, IL-4 and IL-13. Whereas, during Th1 and Th17 associated infection, neutrophils respond by release of ROS and aid in the promotion of an inflammatory environment. In order to examine the presence of a phenotype shift during these studies, IL-17 expression was observed over the same time course as Th2 associated genes were. Our data indicates a downregulation of IL-17 expression during $H$. contortus antigen processing, providing evidence in favor of neutrophils adaptability to stimulus.

Gene expression analysis of Th2 associated genes (IL-4, IL-13, IL-4R $\alpha$, and Stat6) revealed upregulation after an hour of $H$. contortus antigen stimulation. Increased transcription at 1 hour after stimulation coincides with production of IL-4 and IL-13 protein observed as early as 3 and 6-hours after larval antigen stimulation. Classically, neutrophils have been known for their vital role in microbial infection clearance through production of proinflammatory cytokines, 
reactive oxygen species (ROS), phagocytosis, and neutrophil extracellular traps, promoting a Th1 response (Mócsai, 2013). Our data suggests an ability of ovine neutrophils to recognize parasitic stimulant in vitro and alter their phenotype by upregulating type 2 associated genes necessary for parasite expulsion.

Data from these studies also confirmed ovine neutrophils ability to communicate with other immune cells. Ovine neutrophils expressed major histocompatibility complex II (MHC II) necessary for extracellular antigen presentation and communication to immune cells. MHC II expression peaked at 1-hour for STC neutrophils and 3-hours for SUF neutrophils. Similarly, human neutrophils have been shown to present influenza hemaaglutinin to antigen-specific CD4 ${ }^{+}$ $\mathrm{T}$ cells in an MHC II- DR dependent manner (Vono et al., 2011). Our data revealed ovine neutrophils from both STC and SUF breeds ability to present exogenous $H$. contortus larval antigen to PBMC and induce IL-4 production and a proliferative response.

Haemonchus contortus infection in sheep is of great importance due to its detrimental nature to economically favorable sheep breeds such as the Suffolk. Jacobs et al., (2016) observed differences in immune responses between parasite-resistant STC and parasite-susceptible SUF sheep. IL-4 expression was found to be upregulated in abomasal tissue within the first 7 days, as early as day 3 in STC sheep. Previous reports support the notion of a 7-day delay in immune responses by the SUF sheep to larval stages, permitting the establishment of adults. In SUF sheep, IL-4 expression was not upregulated until day 10-post H. contortus infection (Jacobs et al., 2016). Characterization of cellular components found in the abomasal tissue of sheep during $H$. contortus infection observed the only difference between STC and SUF breeds were in neutrophil presence. Neutrophil presence by day 3-post infection was significantly higher in STC than in SUF abomasal tissue, that trend continued out to day 7 (Bowdridge et al., 2015). In vivo differences in resistant 
and susceptible breeds point toward recruitment of neutrophils to the site of infection. In vitro analysis of neutrophil function after $H$. contortus antigen stimulation reveals no functional differences between breeds however; there are differences in neutrophil responses to larval stages as compared to responses to adult stages.

The ability of neutrophils to migrate to site of infection in resistant STC sheep early during H. contortus infection, and their ability to produce both IL-4 and IL-13 provide a framework for early responses initiating resistance. The lack of breed differences observed in in vitro analysis provides evidence that a defect in the effector function of SUF neutrophils may not be the cause of delayed responses. In vivo analysis has shown a reduction in neutrophil recruitment at the site of infection with SUF sheep, which may cause the delays observed in SUF immune responses. Future studies remain to be performed to understand the dysfunction in neutrophil recruitment in susceptible SUF sheep. An understanding of this phenomenon may allow for the development of therapies that would induce neutrophil migration would be beneficial in conferring parasite resistance in economically-relevant breeds of sheep. 
Table 1

Table 1. TaqMan Probes

\begin{tabular}{|l|l|l|}
\hline Gene Name & Abbr. & Assay ID \\
\hline Glyceraldehyde3-phosphate & GAPDH & Bt03210913_g1 \\
\hline Interleukin-4 & IL-4 & Oa04927178_s1 \\
\hline Major histocompatibility complex II & MHC II & Oa04925564_s1 \\
\hline
\end{tabular}




\section{Table 2}

Table 2. SYBR Green Primers

\begin{tabular}{|l|l|l|l|}
\hline Gene Name & Abbr. & Primer & Accession\# \\
\hline Glyceraldehyde3-phosphate & GAPDH & F-CAGGAGCACGAGAGGAAGAG & HM043737 \\
& & R-AATGTATGGAGGTCGGGAGA & \\
\hline Interleukin-13 & IL-13 & F-ACTGGGGTTAGGAGGGACTG & DQ679798.1 \\
& R-ATGCCCACTGCTTTAGTGCT & \\
\hline Interleukin-4 receptor $\mathbf{1}$ & IL-4Ra & F-TGGGAAGAGACGGAGTTTTG & XM_004020855 \\
activator of transcription 3 & & R-GCTTGGCAGGATGTTTGTTT & \\
\hline Signal transducer and & STAT6 & F-GCGTGTGAGTGTGTGTCCT & \\
activator of transcription6 & & R-ACACTCCCTCCCACATACACA & \\
\hline Interleukin-17 & IL-17 & F-GGAACACGAACTCCAGAAGG & XM_004018887.1 \\
& & R-ACTTGGCCTCCCAGATCAC & \\
& & & \\
\hline
\end{tabular}




\section{Figure 2}

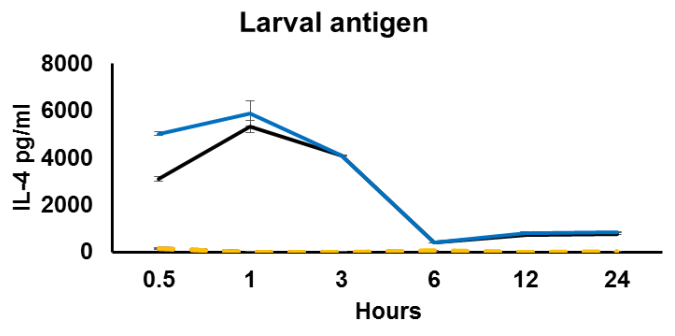

- -STC media - STC HCLA

- SUF media _-SUF HcLA

c

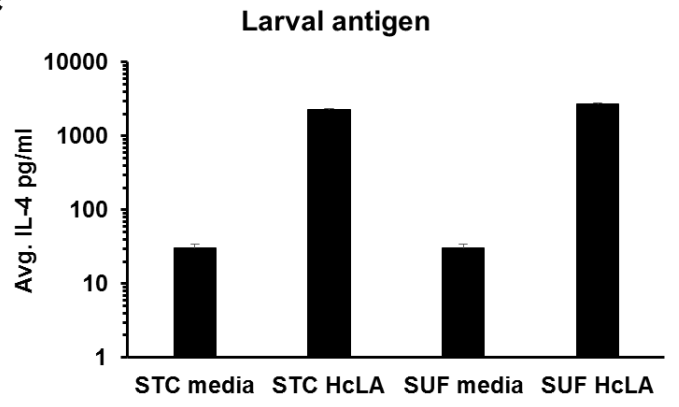

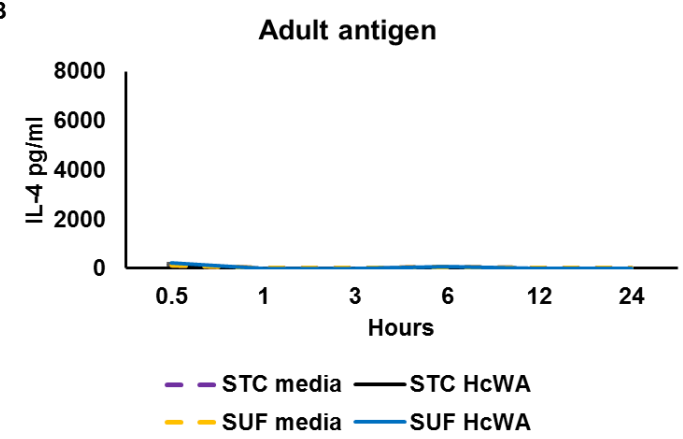

D

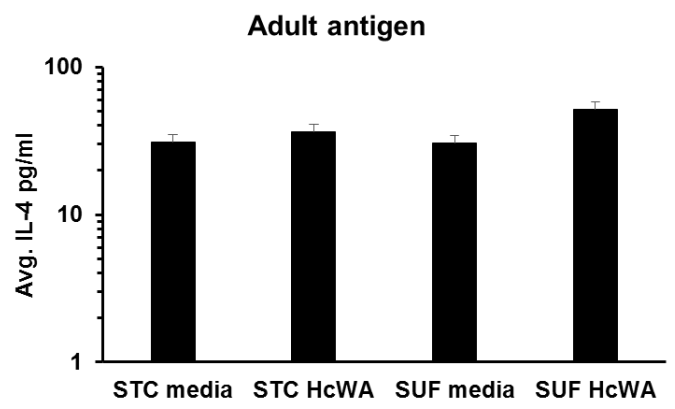

Figure 2: Neutrophils IL-4 production in response to stimulation with larval (HcLA) or adult (HcWA) antigen. St. Croix (STC) and Suffolk (SUF) neutrophils were cultured with $20 \mu \mathrm{g} / \mathrm{ml}$ of $\mathrm{HcLA}(\mathrm{A})$, or HcWA (B) for $0.5,1,3,6,12$, or 24 hours. Average IL-4 protein was measured over the time course for larval (C), or adult (D) antigen stimulation. Interleukin-4 protein in cell supernatant was measured by an ovine specific IL-4 ELISA. Error bars $=$ SEM. 
Figure 3

A

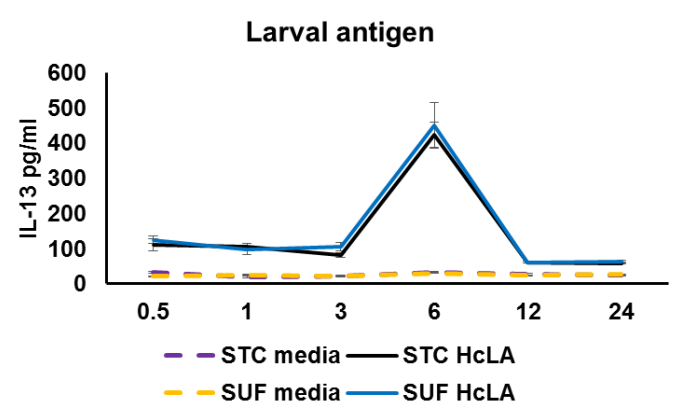

c

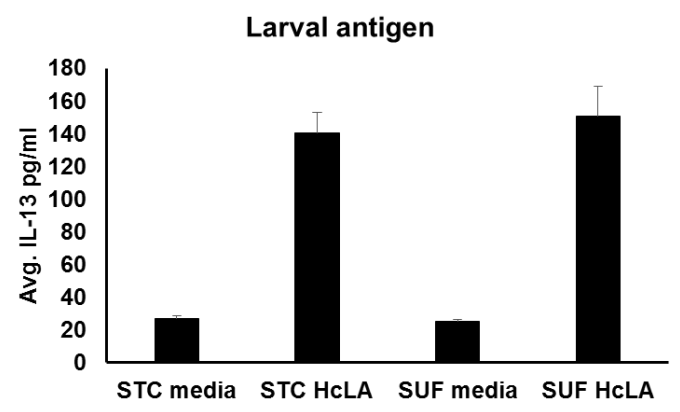

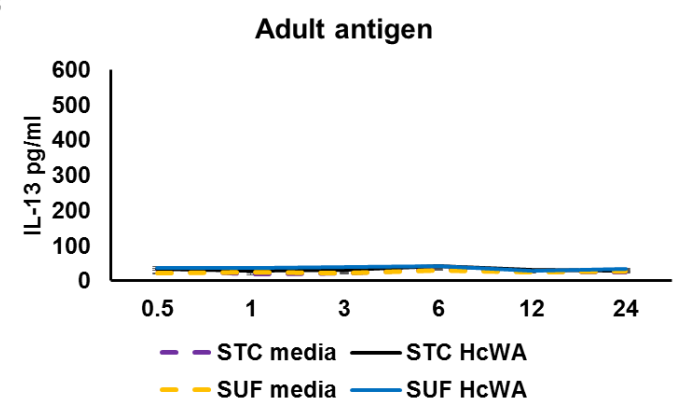

D

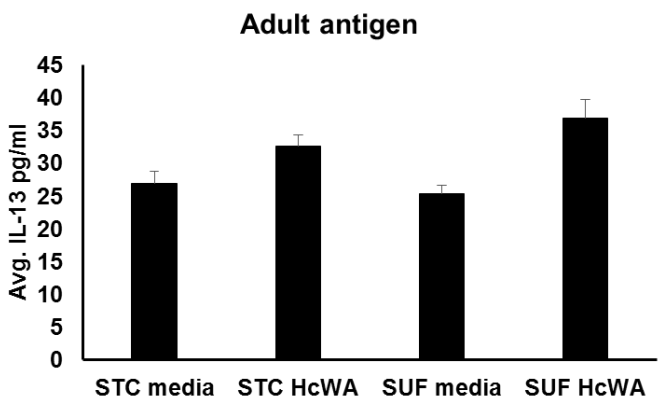

Figure 3: Neutrophils IL-13 production in response to stimulation with larval (HcLA) or adult (HcWA) antigen. St. Croix (STC) and Suffolk (SUF) neutrophils were cultured with $20 \mu \mathrm{g} / \mathrm{ml}$ of $\operatorname{HcLA}(A)$, or HcWA (B) for $0.5,1,3,6,12$, or 24 hours. Average IL-13 protein was measured over the time course for larval (C), or adult (D) antigen stimulation. Interleukin-13 protein in cell supernatant was measured by an ovine specific IL-13 ELISA. Error bars $=$ SEM. 
Figure 4

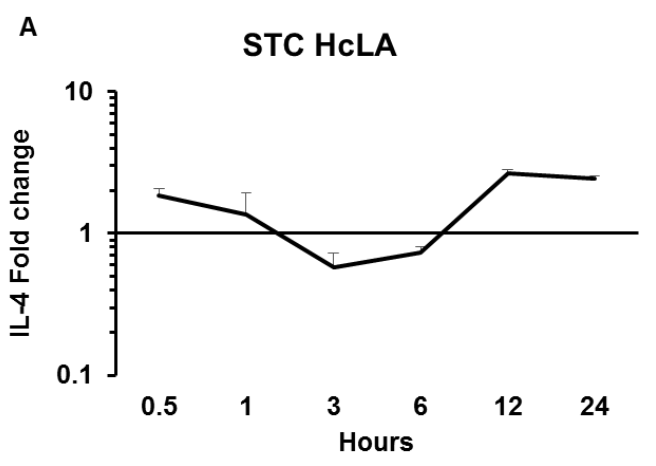

B
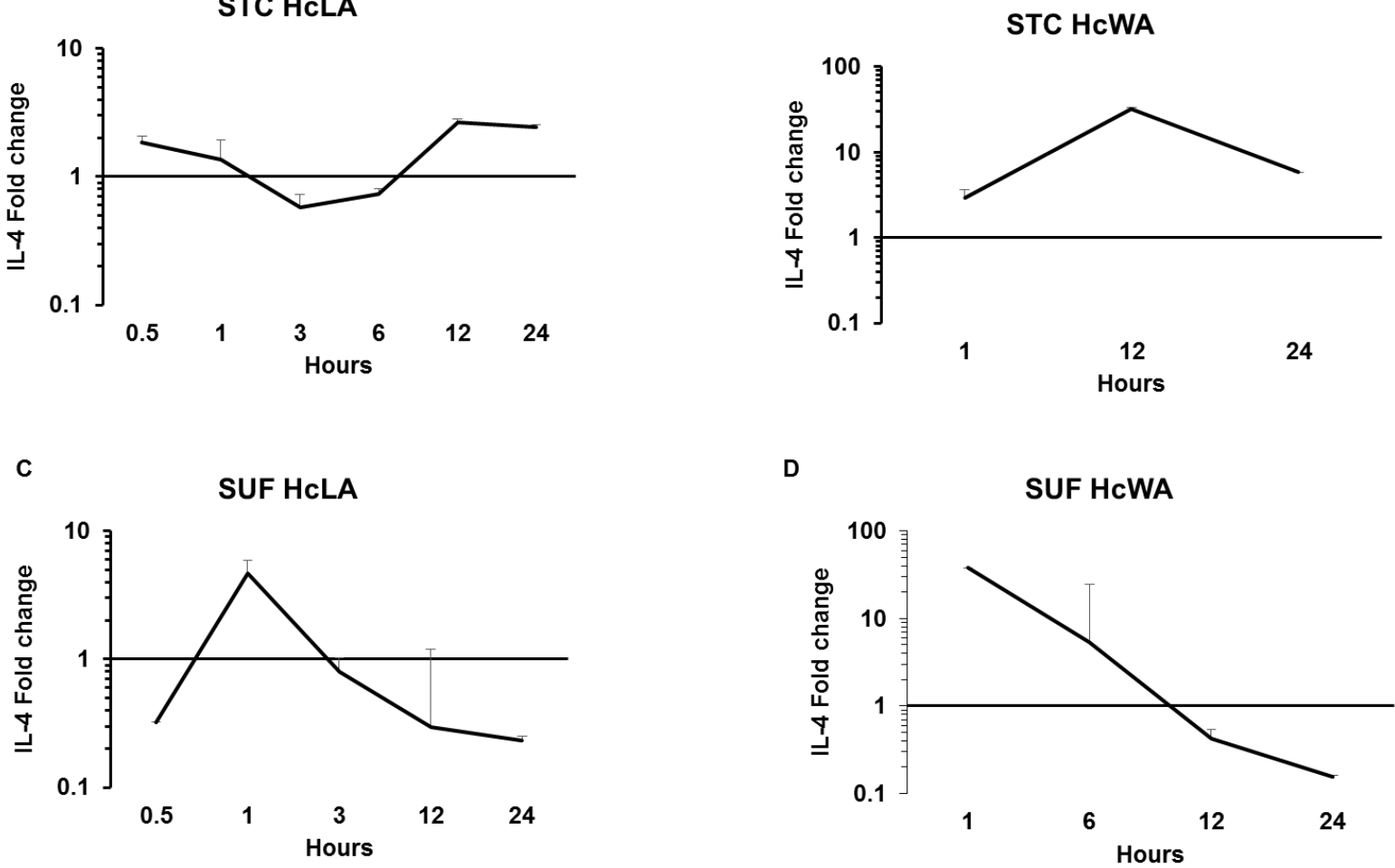

D

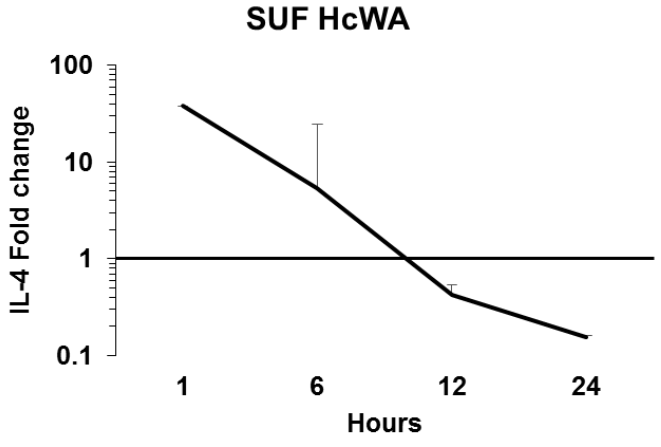

E Larval antigen

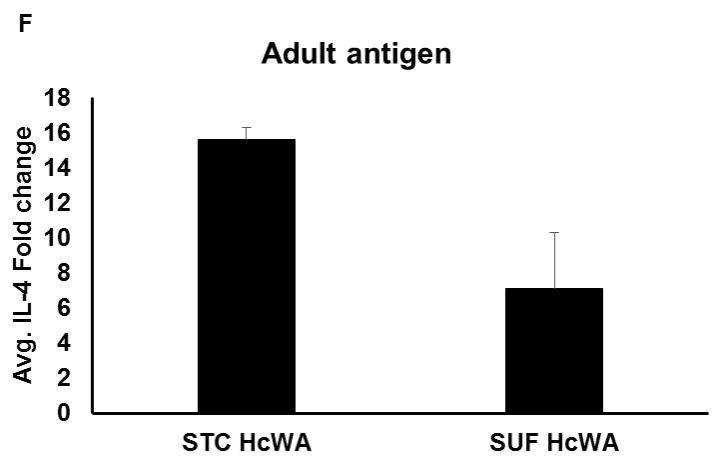

Figure 4: mRNA analysis of primed Suffolk and primed St. Croix neutrophils by qPCR in response to culture with parasitic antigen. Neutrophils from primed SUF and STC sheep were incubated with $20 \mu \mathrm{g} / \mathrm{ml}$ of HcLA or HcWA for $0.5,1,3,6,12$, or 24 hours before RNA extraction for IL-4 gene expression analysis. STC HcLA (A), STC HcWA (B), SUF HcLA (C), SUF HcWA (D), average IL-4 expression over time after larval antigen stimulation $(\mathrm{E})$, and average $\mathrm{IL}-4$ expression over time after adult antigen stimulation $(F)$. Missing time point were undetectable. 
Figure 5

A

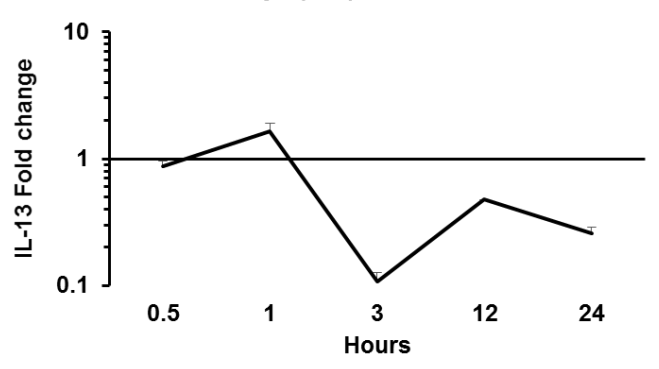

C

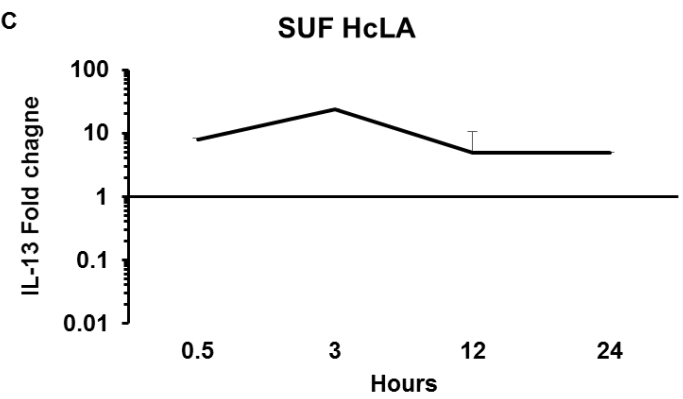

$E$

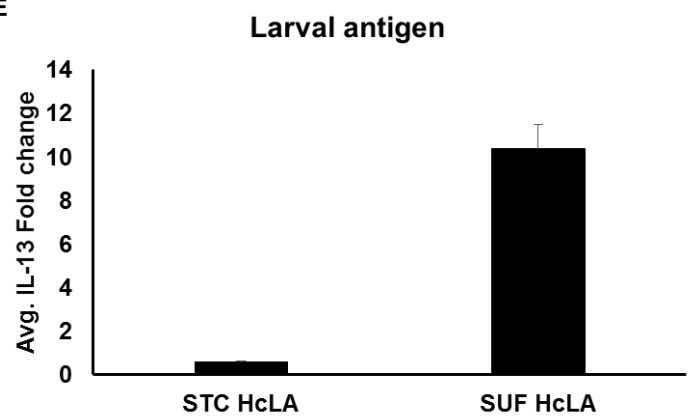

B

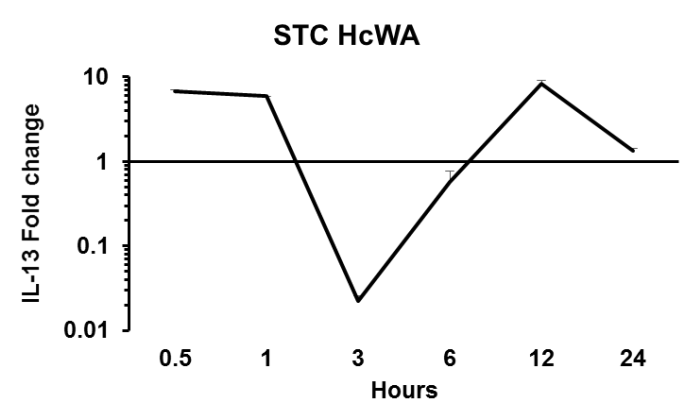

D

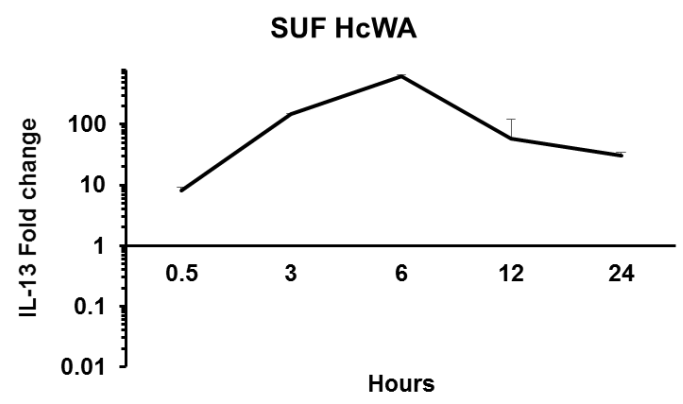

F

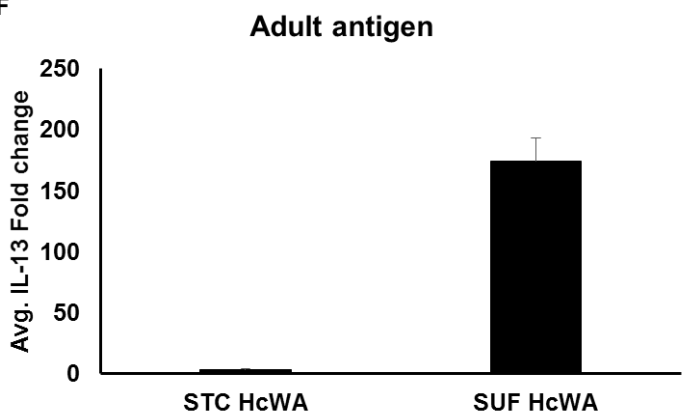

Figure 5: mRNA analysis of primed Suffolk and primed St. Croix neutrophils by qPCR in response to culture with parasitic antigen. Neutrophils from primed SUF and STC sheep were incubated with $20 \mu \mathrm{g} / \mathrm{ml}$ of HcLA or HcWA for $0.5,1,3,6,12$, or 24 hours before RNA extraction for IL-13 gene expression analysis. STC HcLA (A), STC HcWA (B), SUF HcLA (C), SUF HcWA (D), average IL-13 expression over time after larval antigen stimulation (E), and average IL-13 expression over time after adult antigen stimulation $(F)$. Missing time point were undetectable. 
Figure 6

A

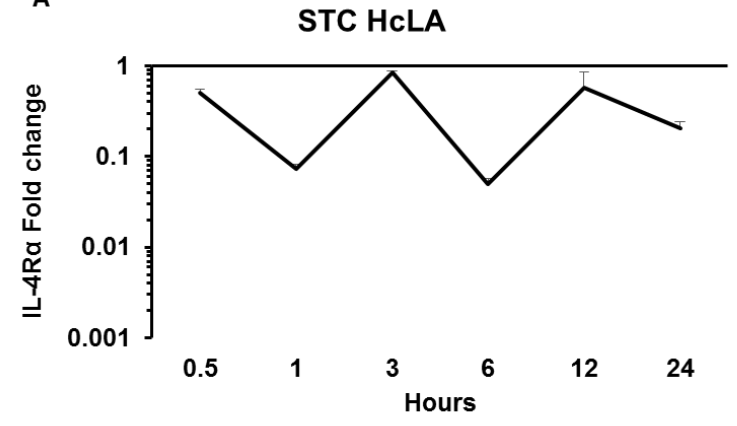

C

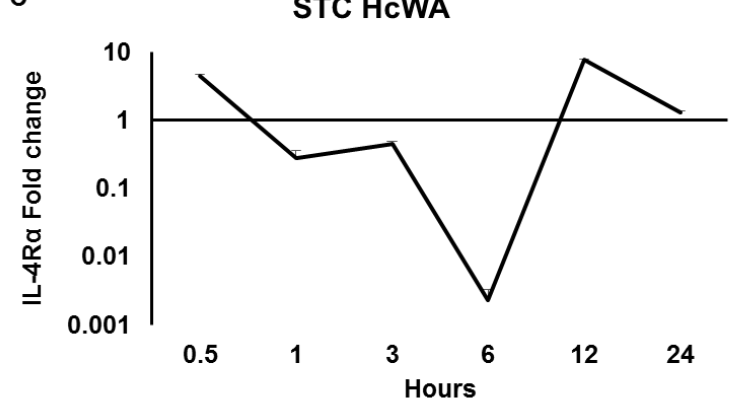

E

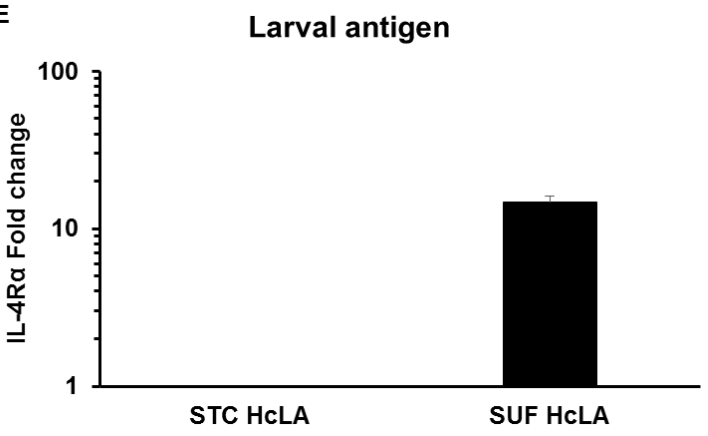

B

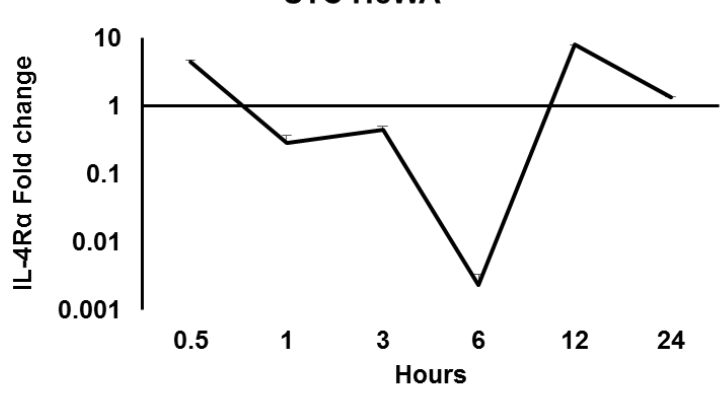

D

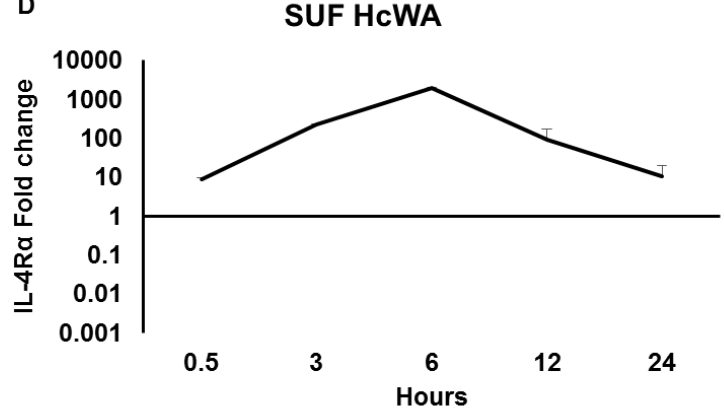

$\mathbf{F}$

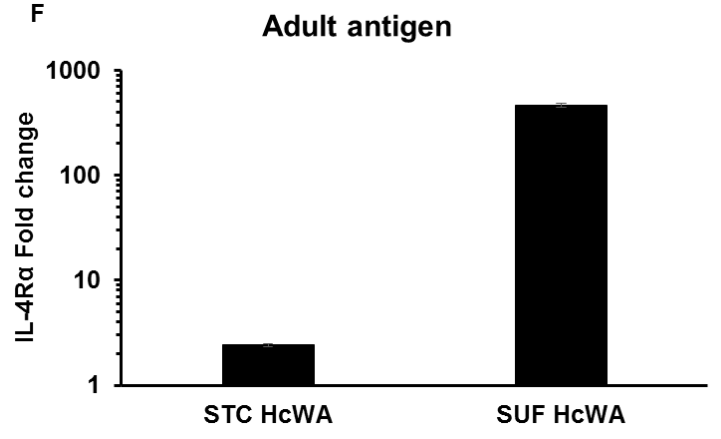

Figure 6: mRNA analysis of primed Suffolk and primed St. Croix neutrophils by qPCR in response to culture with parasitic antigen. Neutrophils from primed SUF and STC sheep were incubated with $20 \mu \mathrm{g} / \mathrm{ml}$ of HcLA or HcWA for $0.5,1,3,6,12$, or 24 hours before RNA extraction for IL-4Ra gene expression analysis. STC HcLA (A), STC HcWA (B), SUF HcLA (C), SUF HcWA (D), average IL-4Ra expression over time after larval antigen stimulation (E), and average IL-4Ra expression over time after adult antigen stimulation $(F)$. Missing time point were undetectable. 
Figure 7

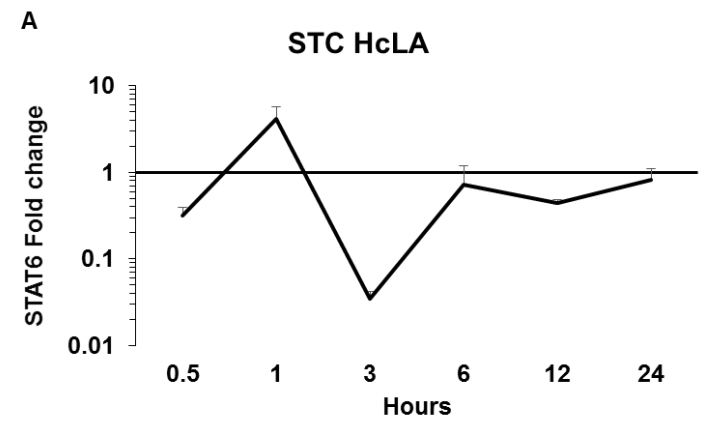

B
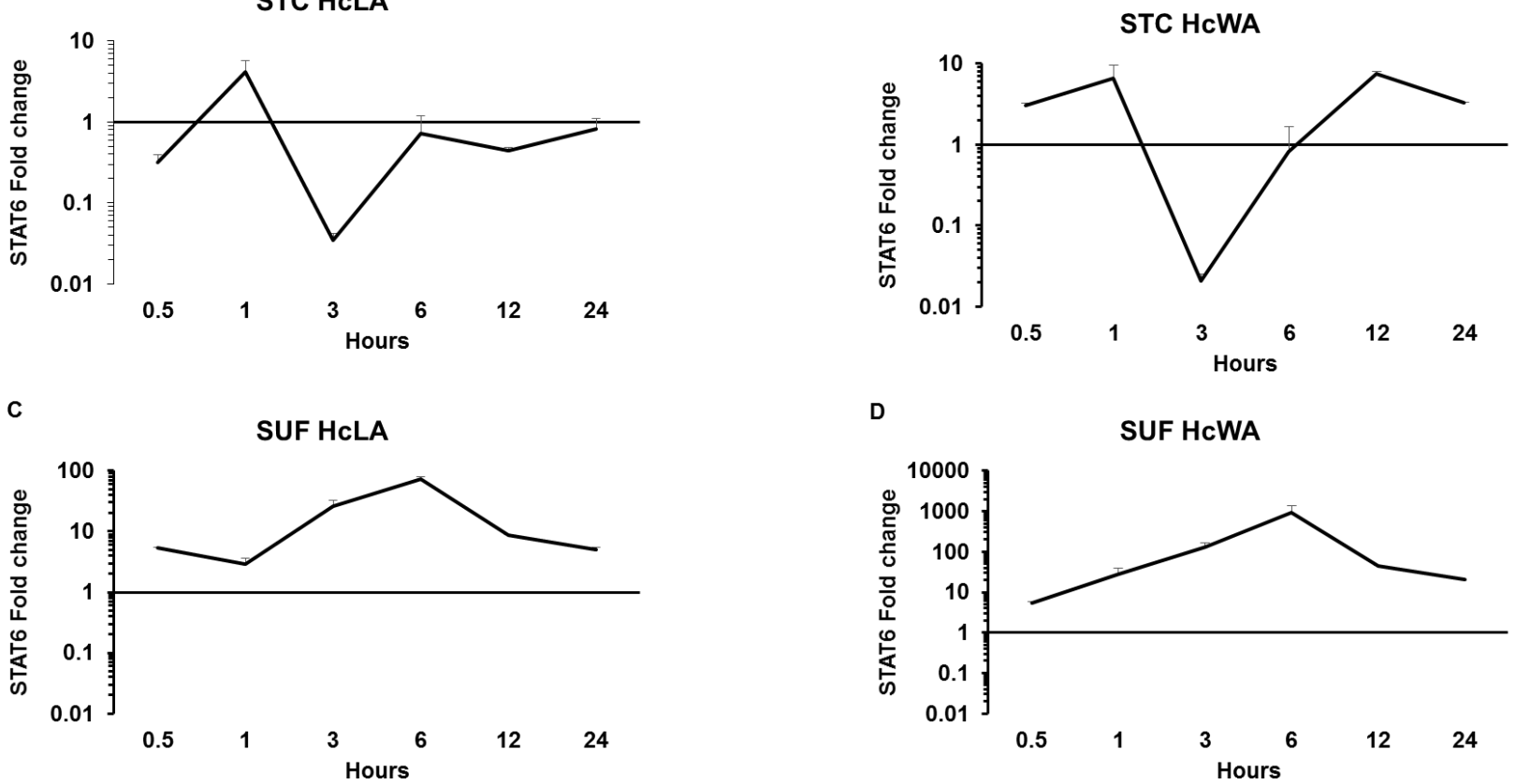

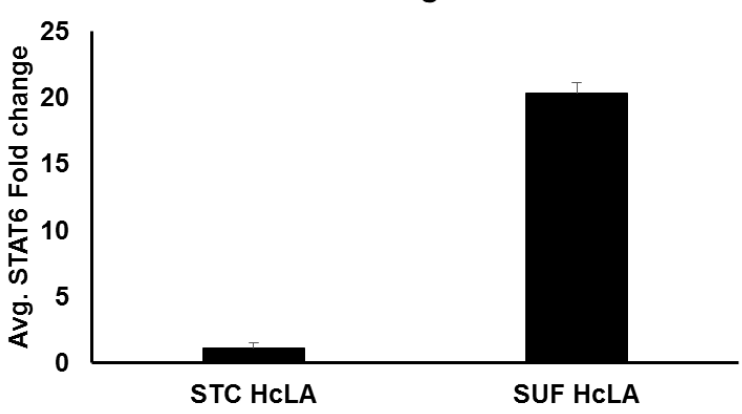

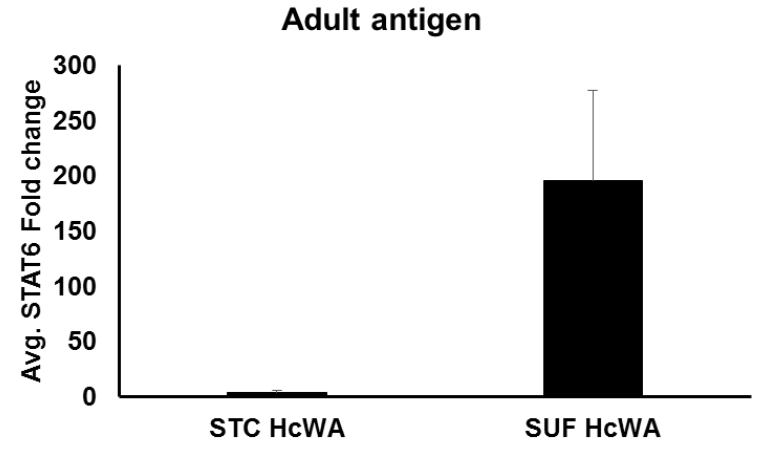

Figure 7: mRNA analysis of primed Suffolk and primed St. Croix neutrophils by qPCR in response to culture with parasitic antigen. Neutrophils from primed SUF and STC sheep were incubated with $20 \mu \mathrm{g} / \mathrm{ml}$ of HcLA or HcWA for $0.5,1,3,6,12$, or 24 hours before RNA extraction for STAT6 gene expression analysis. STC HcLA (A), STC HcWA (B), SUF HcLA (C), SUF HcWA (D), average STAT6 expression over time after larval antigen stimulation (E), and average STAT6 expression over time after adult antigen stimulation (F). Missing time point were undetectable. 
Figure 8

A

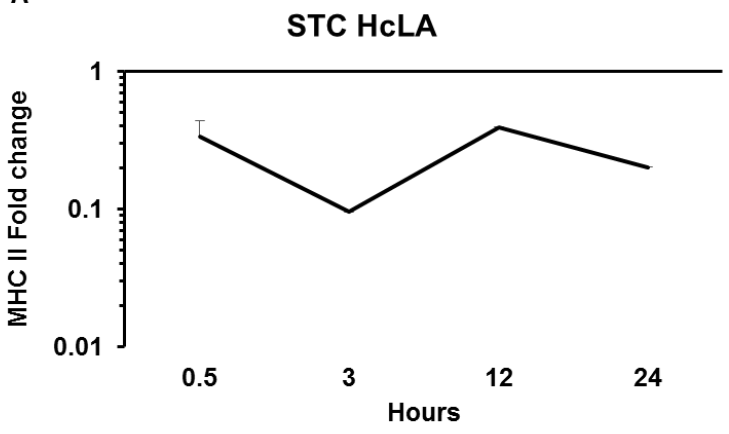

C

SUF HcLA

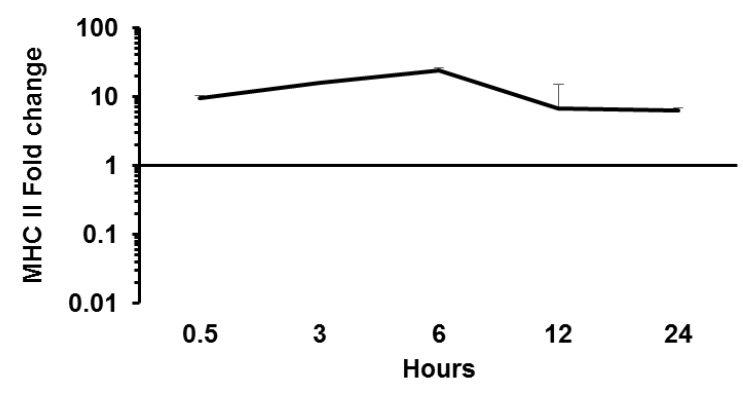

$E$

Larval antigen

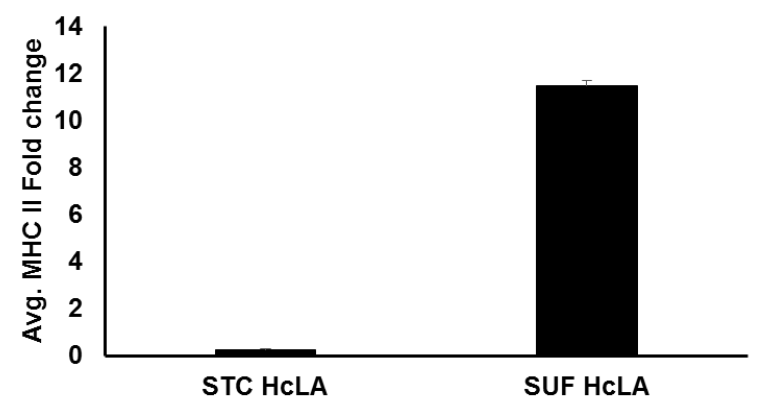

B

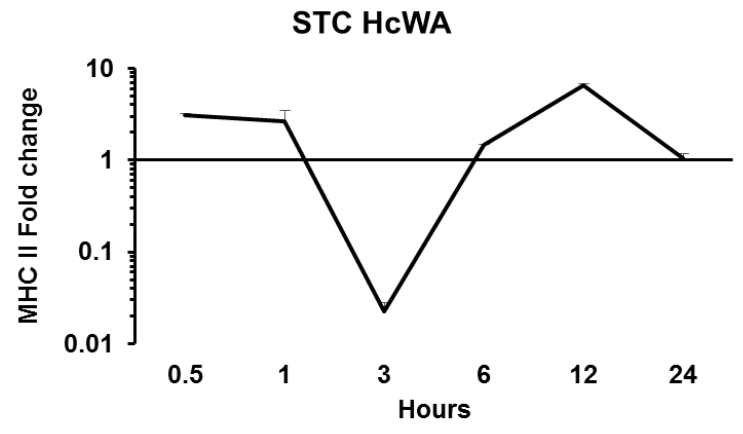

D

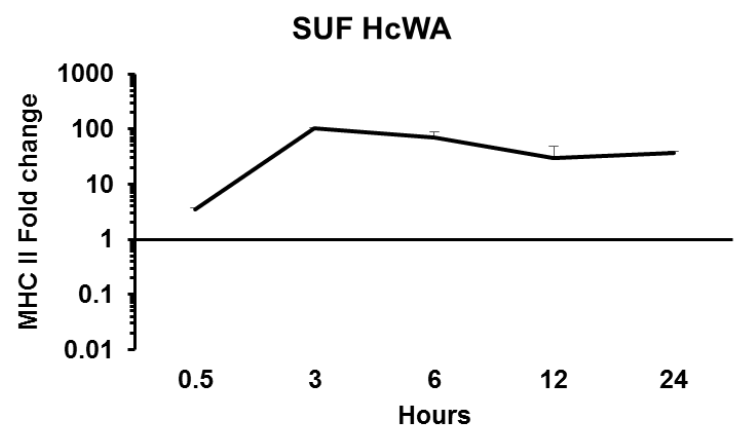

$\mathbf{F}$

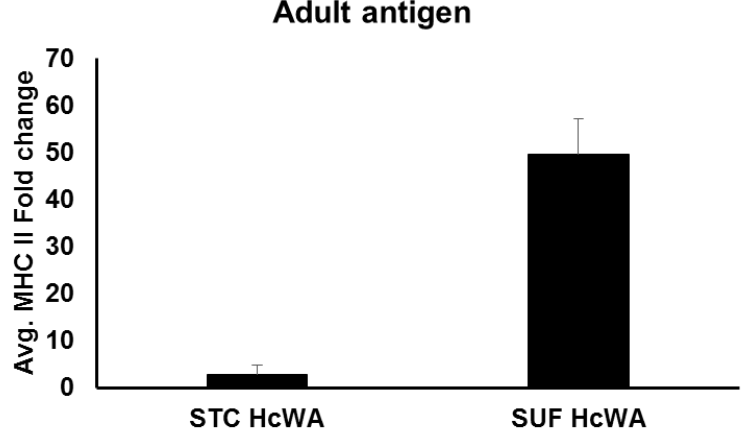

Figure 8: mRNA analysis of primed Suffolk and primed St. Croix neutrophils by qPCR in response to culture with parasitic antigen. Neutrophils from primed SUF and STC sheep were incubated with $20 \mu \mathrm{g} / \mathrm{ml}$ of HcLA or HcWA for $0.5,1,3,6,12$, or 24 hours before RNA extraction for MHC II gene expression analysis. STC HcLA (A), STC HcWA (B), SUF HcLA (C), SUF HcWA (D), average MHC II expression over time after larval antigen stimulation (E), and average $\mathrm{MHC}$ II expression over time after adult antigen stimulation (F). Missing time point were undetectable. 
Figure 9

A

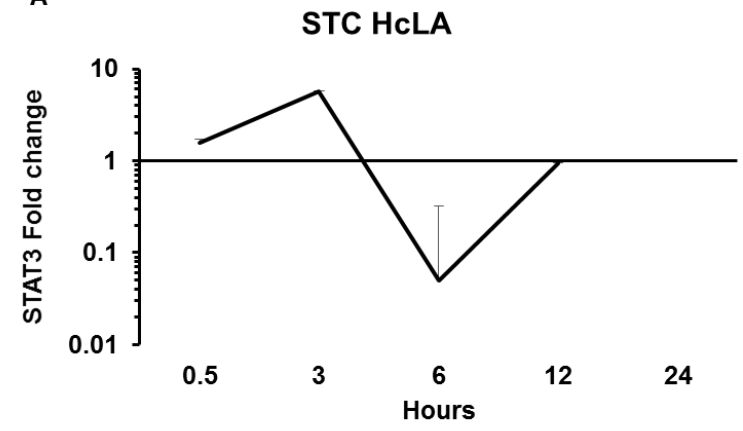

c

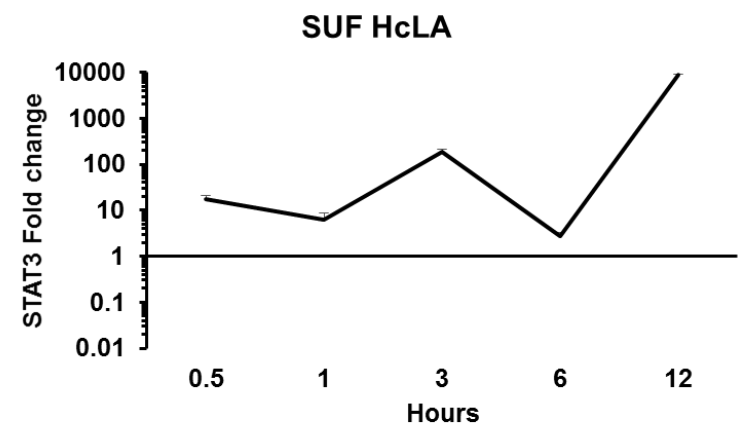

E

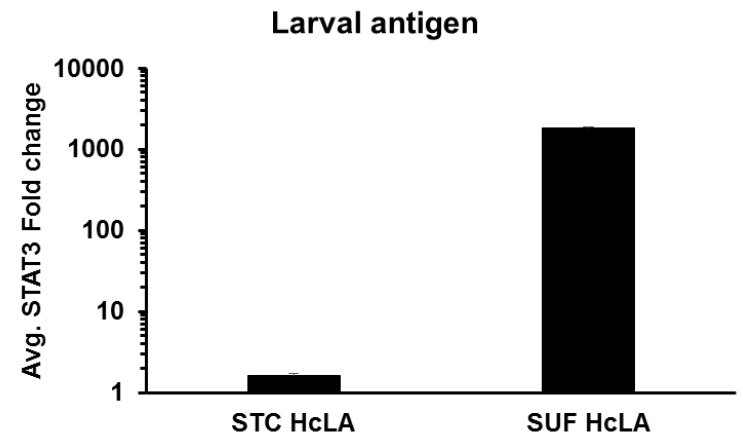

B

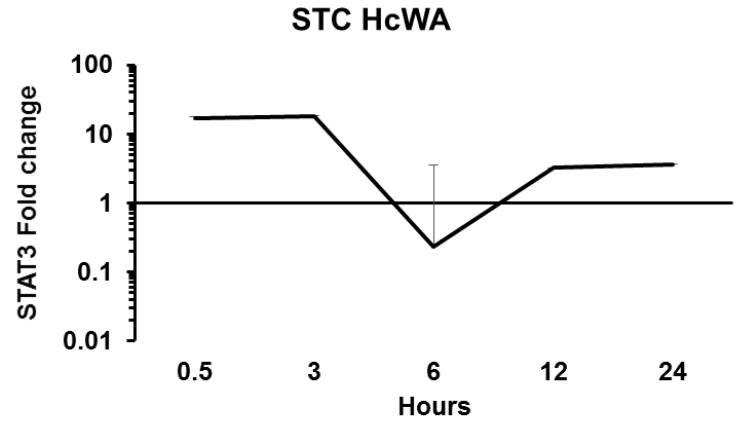

D

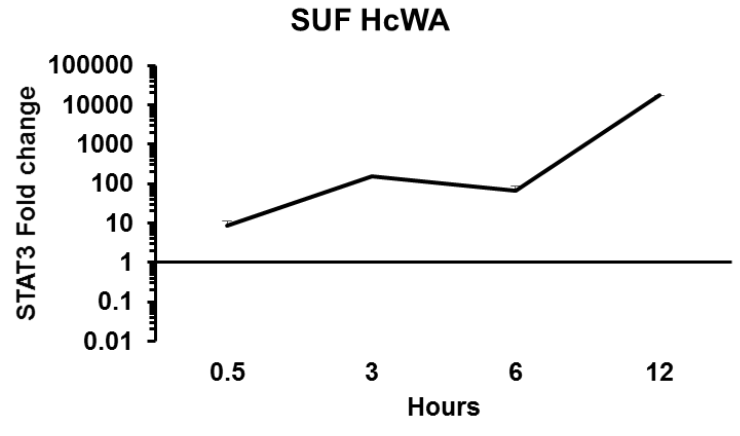

$\mathbf{F}$

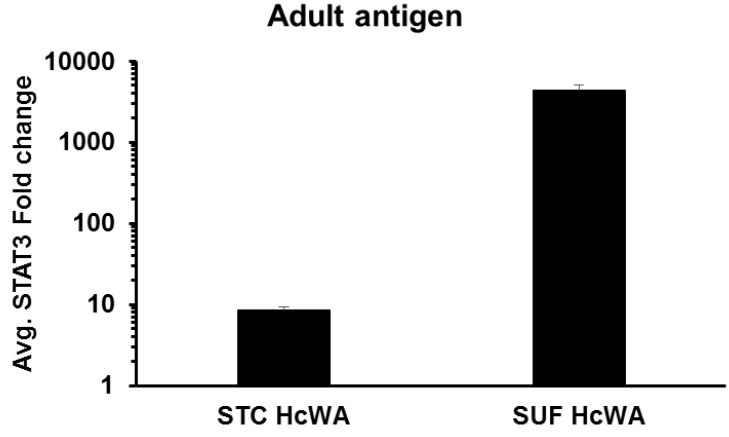

Figure 9: mRNA analysis of primed Suffolk and primed St. Croix neutrophils by qPCR in response to culture with parasitic antigen. Neutrophils from primed SUF and STC sheep were incubated with $20 \mu \mathrm{g} / \mathrm{ml}$ of HcLA or HcWA for $0.5,1,3,6,12$, or 24 hours before RNA extraction for STAT3 gene expression analysis. STC HcLA (A), STC HcWA (B), SUF HcLA (C), SUF HcWA (D), average STAT3 expression over time after larval antigen stimulation (E), and average STAT3 expression over time after adult antigen stimulation (F). Missing time point were undetectable. 
Figure 10

A

Larval antigen

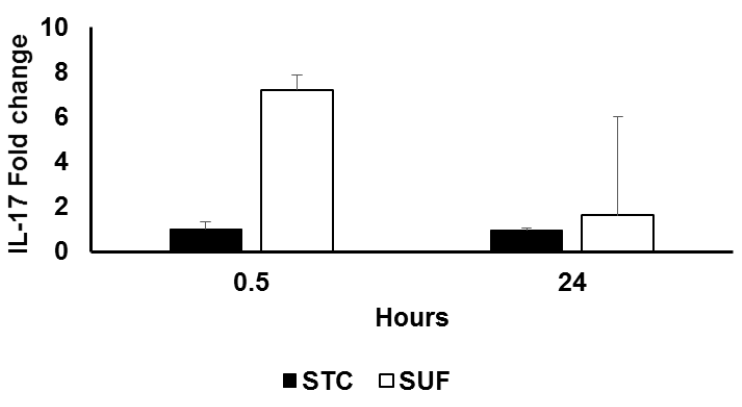

C

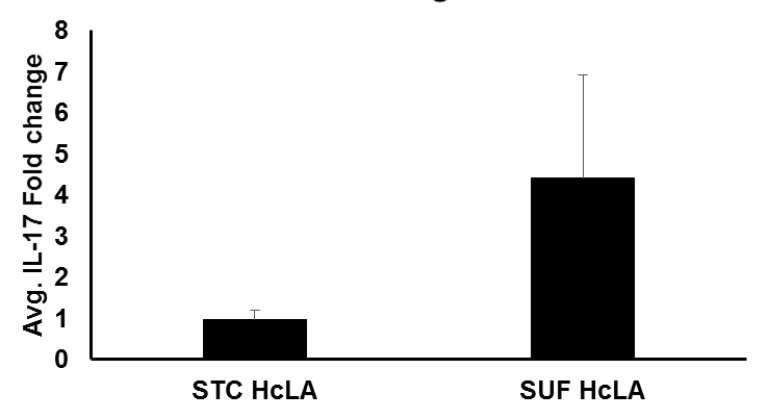

B

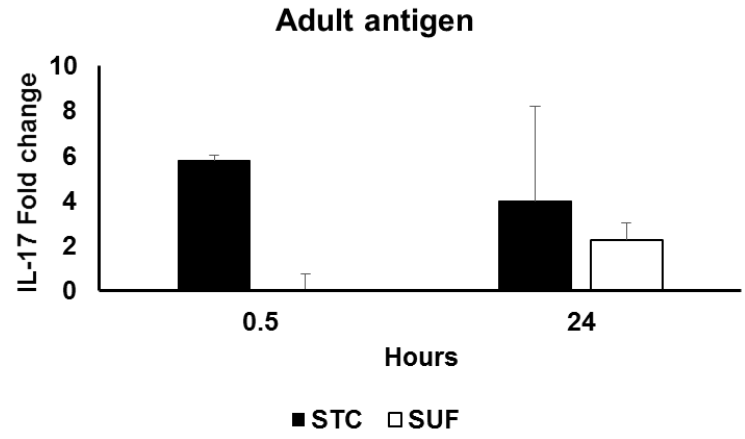

D

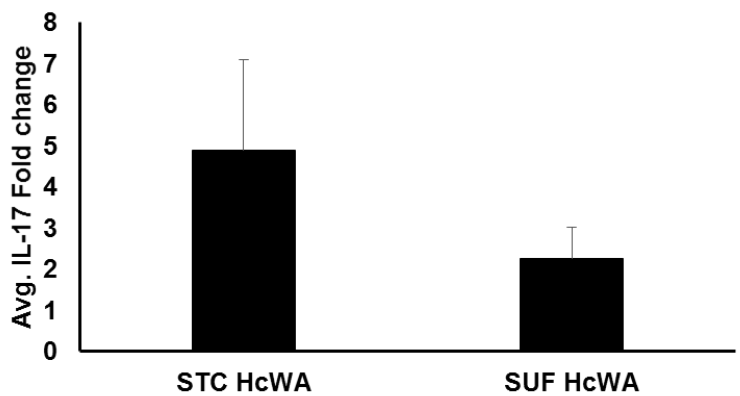

Figure 10: mRNA analysis of primed Suffolk and primed St. Croix neutrophils by qPCR in response to culture with parasitic antigen. Neutrophils from primed SUF and STC sheep were incubated with $20 \mu \mathrm{g} / \mathrm{ml}$ of HcLA or HcWA for $0.5,1,3,6,12$, or 24 hours before RNA extraction for IL-17 gene expression analysis. Larval antigen (A), adult antigen (B), average IL-17 expression over time after larval antigen stimulation (C), and average IL-17 expression over time after adult antigen stimulation (D). Missing time point were undetectable. 


\section{Figure 11}

A

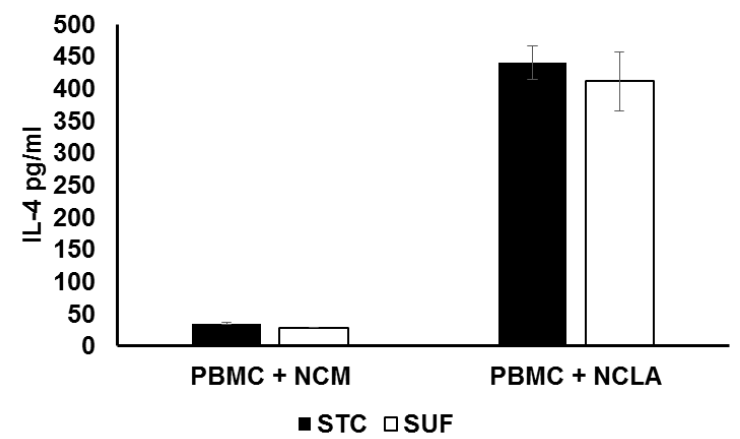

B

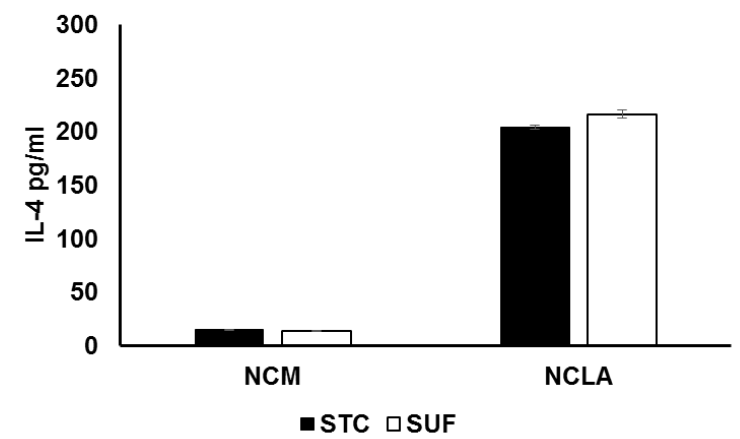

C

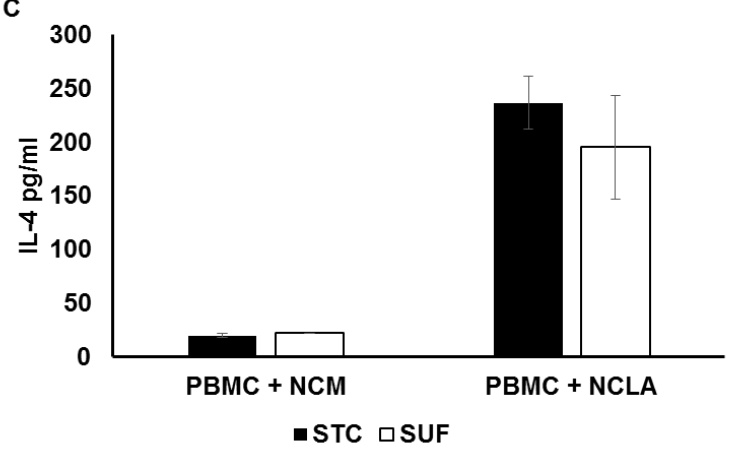

Figure 11: Interleukin-4 production by PBMC stimulated with supernatant from $\boldsymbol{H}$. contortus antigen stimulated neutrophils. Neutrophils were incubated with larval antigen at $20 \mu \mathrm{g} / \mathrm{ml}$ for 3 hours before a 6 -hour co-culture with peripheral blood mononuclear cell (PBMC) to assess IL-4 protein production. Total IL-4 production (A), Neutrophil IL-4 production after 9 hours (B), and IL-4 production by PBMC post stimulation with neutrophil supernatant $(C)$. To obtain the values observed in figure $5 C$, figure 5B was subtracted from figure 5A. NCM: neutrophils stimulated with complete media, NCLA: neutrophils stimulated with HCLA. NCM: neutrophils stimulated with complete media, NCLA: neutrophils stimulated with HcLA. 
Figure 12
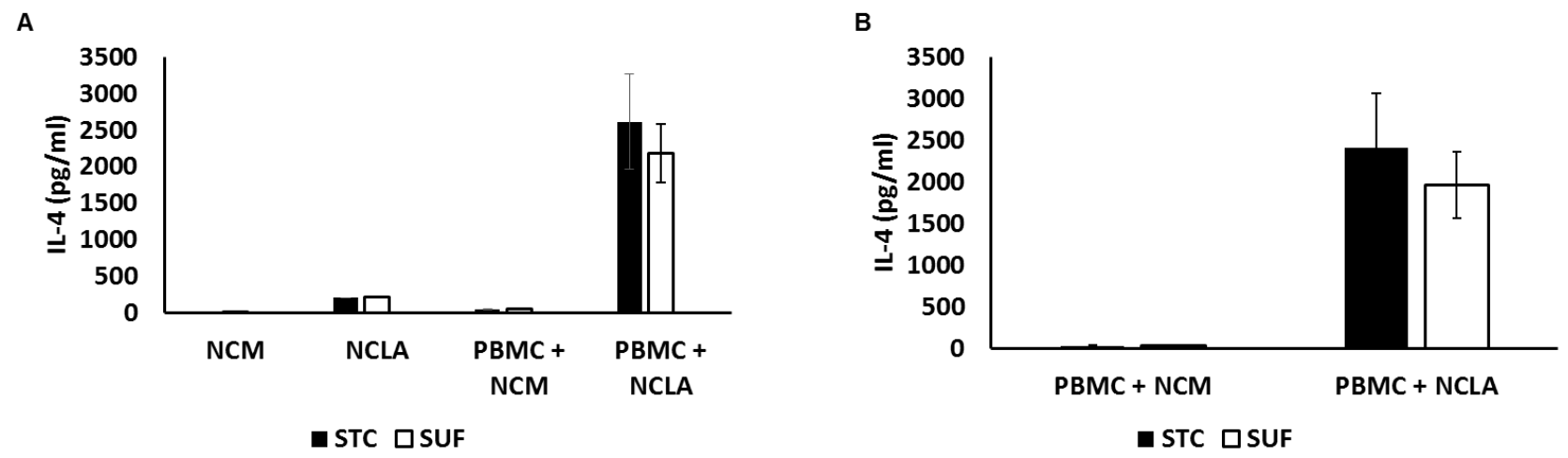

Figure 12: Antigen primed neutrophils incubated with naïve PBMC to assess PBMC IL-4 production. Neutrophils were incubated with larval antigen at $20 \mu \mathrm{g} / \mathrm{ml}$ for 3 hours and washed with sterile PBS. Neutrophils were then co-culture with naive peripheral blood mononuclear cell (PBMC) for 6 hours to assess IL-4 protein production. Total IL-4 production by each group, including neutrophils alone, after 9 hours (A) and IL-4 production by PBMC post stimulation with antigen stimulated neutrophils (B). NCM: neutrophils stimulated with complete media, NCLA: neutrophils stimulated with HcLA. 
Figure 13

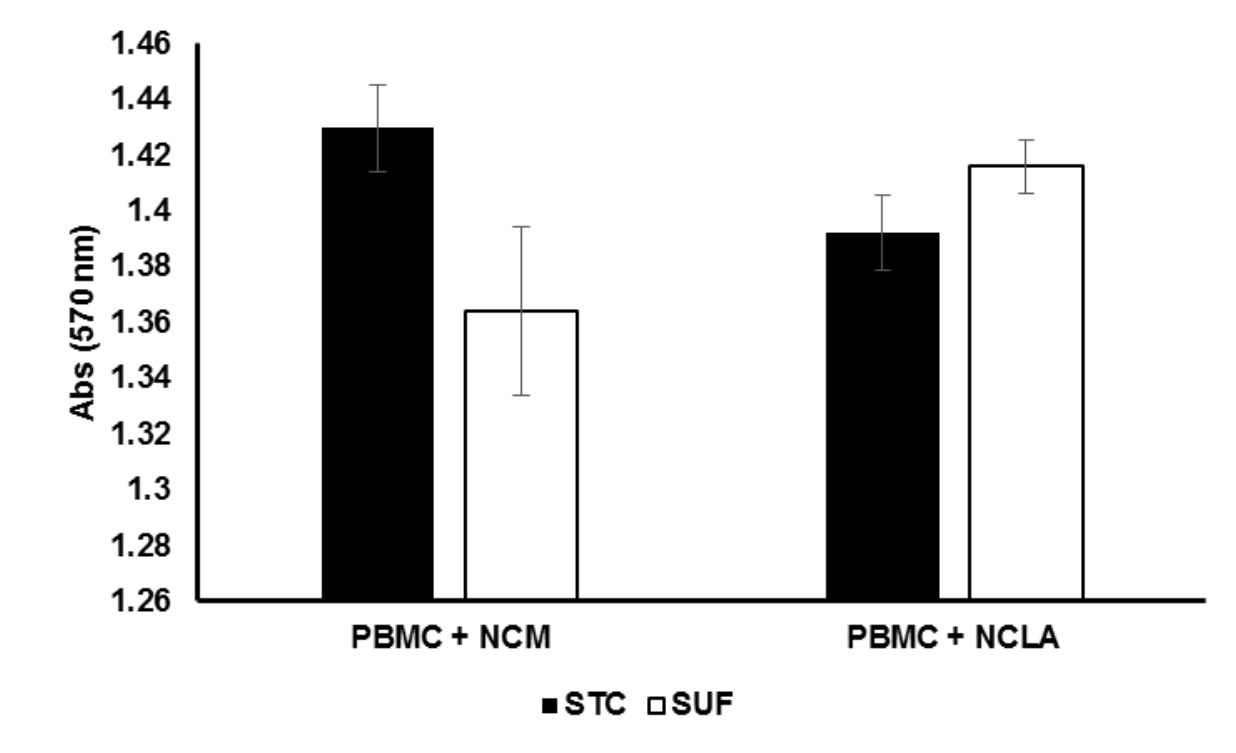

Figure 13: Proliferation assay to assess PBMC responsiveness after culture with $\boldsymbol{H}$. contortus antigen stimulated neutrophils. Neutrophils were incubated for 3 hours with larval antigen at $20 \mu \mathrm{g} / \mathrm{ml}$. After stimulation neutrophils were washed and co-cultured with peripheral blood mononuclear cells (PBMC) for 72 hours, before an alamar blue assay was performed to assess PBMC proliferation. 


\section{Literature Cited:}

Anthony, R .M., Urban, J. F., Jr., Alem F., Hamed, H. A., Rozo, T., Boucher, J. L., . . Gause, W. C. (2006). Memory T(H)2 cells induce alternatively activated macrophages to mediate protection against nematode parasites. Nat Med., 12, 955-960.

Alba-Hurtado, F., \& Munoz-Guzman, M. A. (2013). Immune Responses Associated with Resistance to haemonchosis in sheep. BioMed Res. Int., 2013, 162158.

Allen, J.E., \& Sutherland, T.E. (2014). Host protective roles of type 2 immunity: parasite killing and tissue repair, flip sides of the same coin. Semin Immunol, 26, 329-340.

Bainton, D. F. (1971). The Development of Neutrophilic Polymorphonuclear Leukocytes In Human Bone Marrow: Origin And Content Of Azurophil And Specific Granules. Journal of Experimental Medicine, 134(4), 907-934. doi:10.1084/jem.134.4.907

Balic, A., Bowles, V. M., \& Meeusen, E. N. T. (2000). Cellular profiles in the abomasal mucosa and lymph node during primary infection with Haemonchus contortus in sheep. Vet. Immunol. Immunopathol., 75, 109-120.

Barger, I. A., et al. (1985). "Regulation of Haemonchus contortus populations in sheep exposed to continuous infection." International Journal for Parasitology, 15(5), 529-533.

Barner, M., Mohrs, M., Brombacher, F., \& Kopf, M. (1998). Differences between IL-4R alphadeficient and IL-4 deficient mice reveal a role for IL-13 in the regulation of Th2 responses. Curr. Biol., 8, 669-672.

Borregaard, N., \& Cowland, J. B. (1997). Granules of the human neutrophilic polymorphonuclear leukocyte. Blood, 89(10), 3503-3521.

Borregaard, N. (2010). Neutrophils, from marrow to microbes. Immunity, 33, 657-670.

Bowdridge, S. A., Zajac, A. M., \& Notter, D. R. (2015). St. Croix sheep produce a rapid and greater cellular immune response contributing to reduced establishment of Haemonchus contortus. Vet. Parasitol., 208, 204-210.

Chaitidis, P., O’Donnell, V., Kuban, R. J., Bermudez-Fajardo, A., Ungetheum, U., \& Kuhn, H. (2005). Gene expression alterations of human peripheral blood monocytes induced by medium term treatment with the TH2-cytokines interleukin-4 and -13. Cytokine, 30, 366377.

Chen, F. (2014). Neutrophils prime a long-lived effector macrophage phenotype that mediates accelerated helminth expulsion. Nat. Immunol., 15(10), 938-946. 
Coffman, R. L., Ohara, J., Bond, M. W., Carty, J., Zlotnik, A., \& Paul, W. E. (1986). B cell stimulatory factor-1 enhances the IgE response of lipopolysaccharide-activated B cells. $J$. Immunol., 136, 4538-4541.

Coffman, R. L., Seymour, B.W., Hudak, S., Jackson, J., \& Rennick, D. (1989). Antibody to interleukin-5 inhibits helminth-induced eosinophilia in mice. Science, 245, 308-310.

Conway, D. P. (1964). Variance in effectiveness of Thiabendazole against Haemonchus contortus in sheep. Am. J. Vet. Res., 25, 844-845.

Cooke, H. J. 1998. Enteric tears: chloride secretion and its neural regulation. News Physiol. Sci. 13:269.

Clark, C. H., Kiesel, G. K., \& Goby, C. H. (1962). Measurements of blood loss caused by Haemonchus contortus infection in sheep. Am. J. Vet. Res., 23, 977-980.

Cua, D. J., \& Tato, C. M. (2010). Innate IL-17 producing cells: the sentinels of the immune system. Nature Rev. Immunol., 10, 479-489.

Dineen, J. K., \& Wagland, B. M. (1966). The dynamics of the host-parasite relationship IV. The response of sheep to graded and to repeated infection with Haemonchus contortus. Parasitology, 56(04), 639. doi:10.1017/s0031182000071663

Drudge, J. H., et al. (1957) Strain variation in the response of sheep nematodes to the action of phenothiazine: II. Studies on pure infections of Haemonchus contortus. Am. J. Vet. Res., $18,317-325$.

Ehigiator, H. N., Stadnyck, A. W., \& Lee, T. D., (2000). Extract of Nippostrongylus brasiliensis stimulates polyclonal type-2 immunoglobulin response by inducing de novo class switch. Infect. Immun., 68, 4913-4922.

Fallon, P. G., et al. (2002). IL-4 induces characteristic TH2 responses even in the combined absence of IL-5, IL-9 and IL-13. Immunity, 17, 7-17.

Finkelman, F. D., Shea-Donohur, T., Goldhill, J., Sullivan, C. A., Morris, S. C., Madden, K. Urban J. F. Jr. (1997). Cytokine regulation of host defense against parasitic gastrointestinal nematodes: Lessons from studies with rodent models. Annu. Rev. Immunol., 15, 505-533.

Fridlender, Z. G., Sun, J., Kim, S., et al. (2009). Polarization of tumor-associated neutrophil phenotype by TGF-beta: "N1" versus "N2" TAN. Cancer Cell. 16(3), 183-194. 10.1016/j.ccr.2009.06.017

Gamble, H. R. \& Zajac, A. M. (1992). Resistance of St. Croix lambs to Haemonchus contortus in experimentally and naturally acquired infections. Vet. Parastiol., 41, 211-225.

Gause, W. C., Urban, J. F., Jr., \& Stadecker, M.J. (2003). The immune response to parasitic helminths: insights from murine models. Trends Immunol., 24, 269-277. 
Gill, H. S., Watson, D. L., \& Brandon, M. R. (1993). Monoclonal antibody to CD4+ T cells abrogates genetic resistance to Haemonchus contortus in sheep. Immunol. 78(1), 43.

Harris, N., \& Gause, W. C. (2011).To B or not to B: B cells and the Th2-type immune response to helminths. Trend Immunol., 3(22), 80-88.

Harvie, M., Camberis, M., \& Le, G. G. (2013). Development of CD4 T cell Dependent immunity against $N$. brasiliensis infection. Front Immunol, 4, 74.

Howell, S. B., Burke, J. M., Miller, J. E., Terrill, T. H., Valencia, E., Williams, M. J., . . R. M. Kaplan. (2008). Prevalence of anthelmintic resistance on sheep and goat farms in the southeastern United States. Am. J.Vet. Res., 233(12), 1913-1919.

Holt, R., Shepherd, E. A., Ammer, A., \& Bowdridge, S. A. (2015). Effects of peripheral blood mononuclear cells on Haemonchus contortus larval motility in vitro. Parasit. Immunol., $37,553-556$.

Horsnell, W. G., Vira, A., Kirstein, F., Mearns, H., Hoving, J. C., Cutler, A. J., Brombacher, F. (2010). IL-4R $\alpha$-responsive smooth muscle cells contribute to initiation of TH2 immunity and pulmonary pathology in Nippostrongylus brasiliensis infections. Mucosal Immunology, 4(1), 83-92. doi:10.1038/mi.2010.46

Hsieh, C. S., Heimberger, A. B., Gold, J.S., o'Garra, A., \& Murphy, K.M. (1992). Differential regulation of T-helper phenotype development by interleukin-4 and interleukin-10 in an alpha-beta-T cell receptor transgenic system. Proc. Natl. Acad. Sci. USA, 89, 6065-6069.

Jacobs, J. R. (2016). Early IL-4 gene expression in abomasum is associated with resistance to Haemonchus contortus in hair and wool sheep breeds. Parasit. Immunol., 38(6), 333-339.

Jeggo, M. H., Wardley, R. C., \& Brownlie, J. (1984). "A study of the role of cell-mediated immunity in bluetongue virus infection in sheep, using cellular adoptive transfer techniques." Immunology, 52(3), 403.

Kaplan, M. H., Schindler, U., Smiley, S. T., Grusby, M. J. (1996). Immunity, 4, 313-319.

Kemp, J. M., Robinson, N. A., Meeusen, E. N. T., \& Pidrafita, D. M. (2009). The relationship between the rapid rejection of Haemonchus contortus larvae with cells and mediators in abomasal tissues in immune sheep. Int. J. Parasitol., 39, 1589-1594.

Keyhani, A., Riazi-Rad, F., Pakzad, S. R., \& Ajdary, S. (2014). Human polymorphonuclear leukocytes produce cytokines in response toLeishmania majorpromastigotes. Apmis, 122(9), 890-897. doi:10.1111/apm.12252 
Kopf, M., Le Gros, G., Bachmann, M., Lamers, M. C., Bluethmann, H., \& Kohler, G. (1993).

Disruption of the murine IL-4 gene blocks Th2 cytokine responses. Nature, 362, 245-248.

Kotze, A., \& Prichard, R. (2016). Anthelmintic Resistance in Haemonchus contortus. Haemonchus Contortus and Haemonchosis - Past, Present and Future Trends Advances in Parasitology, 397-428. doi:10.1016/bs.apar.2016.02.012

Kreider, T., Anthony, R. M., Urban, J. F., Jr, \& Gause, W. C. (2007). Alternatively activated macrophages in helminth infections. Curr. Opin. Immunol., 19, 448-453.

Kubes, P., \& Deniset, J. (2016). Faculty of 1000 evaluation for Neutrophils prime a long-lived effector macrophage phenotype that mediates accelerated helminth expulsion. F1000 Post-publication peer review of the biomedical literature. doi:10.3410/f.718551182.793526415

Lacroux, C., Nguyen, T.H.C., Andreoletti, O., Prevot, F., Grisez, C., Bergeaud, J. P. Jaquiet, P. (2006). Haemonchus contortus (Nematode: Trichostrongylidae) infection in lambs elicits an unequivocal Th2 immune response. Vet. Res., 37, 607-622.

Iademarco, M. F., Barks, J. L., \& Dean, D. C. (1995). Regulation of vascular cell adhesion molecule-1 expression by IL-4 and TNF-alpha in cultured endothelial cells. Journal of Clinical Investigation, 95(1), 264-271. doi:10.1172/jci117650

Le Gros, G., Schultze, N., Walti, S., Einsle, K., Finkelman, F., Kosco-Vilbois, M. H., \& Heusser C. (1996). The development of $\operatorname{IgE}^{+}$memory B cells following primary $\operatorname{IgE}$ immune responses. Eur. J. Immunol., 26, 3042-3047.

Madden, K. B., Urban, J. F., Jr, Ziltener, H. J., Schrader, J. W., Finkelman, F. D., et al. (1991). Antibodies to IL-13 and IL-4 suppress helminth-induced intestinal mastocytosis. $J$. Immunol., 147, 1387-1391.

Madden, K. B., Whitman, L., Sullivan, C., Gause, W. C., Urban, J. F., Katona, I. M., . . SheaDonohue, T. (2002). Role of STAT6 and Mast Cells in IL-4- and IL-13-Induced Alterations in Murine Intestinal Epithelial Cell Function. The Journal of Immunology, 169(8), 4417-4422. doi:10.4049/jimmunol.169.8.4417

Manz, M. G., \& Boettcher, S. (2014). Emergency granulopoiesis. Nature Reviews Immunology, 14(5), 302-314. doi:10.1038/nri3660

Ma, Y., Yabluchanskiy, A., Iyer, R. P., et al. (2016). Temporal neutrophil polarization following myocardial infarction. Cardiovasc. Res., 110(1), 51-61. 10.1093/cvr/cvw024 
MacKinnon, K. M. (2015). Gene expression profiles of hair and wool sheep reveal importance of Th2 immune mechanisms for increased resistance to. J. Anim. Sci., 93(5), 2074-2082.

McKenzie, G. J., Fallon, P. G., Emson, C. L., Grencis, R. K., \& McKenzie A. N. (1999). Simultaneous Disruption of interleukin-4 and IL-13 defines individual roles in T helper cell type 2- mediated responses. J. Exp. Med., 189, 1565-1572.

Mederos, A.E., Ramos, Z. Banchero, G.E., 2014. First report of monepantel Haemonchus contortus resistance on sheep farms in Uruguay. Parasit. Vectors 7, 598.

Minty, A., Chalon, P., Derocq, J. M., Dumont, X., Guillemot, J. C, et al. (1993). Interleukin-13 is a new human lymphokine regulating inflammatory and immune responses. Nature, 362, 248-250.

Miller, J., Bahirathan, M., Lemarie, S., Hembry, F., Kearney, M., \& Barras, S. (1998). Epidemiology of gastrointestinal nematode parasitism in Suffolk and Gulf Coast Native sheep with special emphasis on relative susceptibility to Haemonchus contortus infection. Veterinary Parasitology, 74(1), 55-74. doi:10.1016/s0304-4017(97)00094-0

Mócsai, A. (2013). Diverse novel functions of neutrophils in immunity, inflammation, and beyond. The Journal of Experimental Medicine, 210(7), 1283-1299. doi:10.1084/jem.20122220

Mortensen, L. L., Williamson, L. H., Terrill, T. H., et al. (2003). Evaluation of prevalence and clinical implications of anthelmintic resistance in gastrointestinal nematodes in goats. $J$. Am. Vet. Med. Assoc., 223, 495-500.

Morimoto, M., et al. (2004). Peripheral CD4 T cells rapidly accumulate at the host: parasite interface during an inflammatory Th2 memory response. J. Immunol., 172, 2424-2430.

Nagashima, S., et al. (2007). Bioorg. Med. Chem., 15, 1044-1055.Neill, D. R. (2010).

Nuocytes represent a new innate effector leukocyte that mediates type-2 immunity. Nature, 464.7293, 1367.

Nathan, C. (2006). Neutrophils and immunity: Challenges and opportunities. Nature Reviews Immunology, 6(3), 173-182. doi:10.1038/nri1785

Nono J. K., Ndlovu, H., Abdel, A. N., Mpotje, T., Hlaka, L., \& Brombacher, F. (2017). Interleukin4 receptor alpha is required after Th2 polarization for the maintanence and the recall of protective immunity to nematode infection. PLoS Negl Trop Dis 11: e0005675. pmid:28651009

Noël, W., et al. (2004). "Alternatively activated macrophages during parasite infections." Trends in parasitology, 20(3), 126-133. 
Noelle, R., Kramme, R. P., Ohara, J., Uhr, J. W., \& Vitetta, E. S. (1984). Increased expression of Ia antigens on resting B cells: an additional role for B cell growth factor. Proc. Natl. Acad, Sci. USA, 81, 6149-6153.

Oshea, J. J. (1997). Jaks, STATs, Cytokine Signal Transduction, and Immunoregulation: Are We There Yet? Immunity, 7(1), 1-11. doi:10.1016/s1074-7613(00)80505-1

Owyang, A. M., et al. (2006). Interleukin 25 regulates type 2 cytokine-dependent immunity and limits chronic inflammation in the gastrointestinal tract. J. Exp. Med., 203, 843-849.

Patel, N., Kreider, T., Urban, J. F., Jr., \& Gause, W. C. (2009). Characterisation of effector mechanisms at the host: parasite interface during the immune response to tissue-dwelling intestinal nematode parasites. Int. J. Parasitol., 39, 13-21.

Paul, W.E. (1991). Blood, 77, 1859-1870.

Pelletier, M., et al. (2010). Evidence for a cross-talk between human neutrophils and Th17 cells. Blood, 115, 335-343.

Presson, B. L., Gray, G. D., \& Burgess, S. K. (1988). The effect of immunosuppression with dexamethasone on Haemonchus contortus infections in genetically resistant Merino sheep. Parasit. Immunol., 10(6), 675-680.

Reglier, H., Arce-Vicioso, M., Fay, M., Gougerot-Pocidalo, M. A., \& Chollet-Martin, S. (1998). Lack Of Il-10 And Il-13 Production By Human Polymorphonuclear Neutrophils. Cytokine, 10(3), 192-198. doi:10.1006/cyto.1997.0272

Seder, R. A., Paul, W. E., Davis, M. M., De, S. T., \& Groth, B. F. (1992). The presence of interleukin-4 during in vitro priming determines the lymphokine-producing potential of $\mathrm{CD}^{+}{ }^{+} \mathrm{T}$ cells from T cell receptor transgenic mice. J. Exp. Med., 176, 1091-1098.

Seder, R. A., \& Paul, W. E. (1994). Acquisition of lymphokine-producing phenotype by CD4 ${ }^{+}$T cells. Annu. Rev. Immunol. 12, 635-673.

Shepherd, E. A., Garza, J. J., Greiner, S. P., \& Bowdridge, S. A. (2017). The effect of ovine peripheral blood mononuclear cells on Haemonchus contortus larval morbidity in vitro. Parasit Immunol. doi:10.1111/pim.12424

USDA - National Agricultural Statistics Service. US Census of Agriculture Homepage. (2006, July 5). $\quad$ Retrieved March 11, 2018, from http://www.bing.com/cr?IG=2BA412917F9C425FB08B486E958EB753\&CID=1006545 FB70B600B10755FF0B6A461DF\&rd=1\&h=A9nFpAwnstGTLbeKkGxtm6cfEyYSO0W y9MhKGu_mLRk\&v=1\&r=http\%3a\%2f\%2fwww.nass.usda.gov\%2f\&p=DevEx,5065.1 
Urban, J. F., Jr., Katona, I. M., \& Finkelman, F. D. (1991a). Heligmosomoides polygyrus: CD4 ${ }^{+}$T cells regulate the IgE response and preotective immunity in mice. Exp. Parasitol., 73, 500511.

Urban, J. F., Jr., Katona I. M., Paul W. E., \& Finkelman F. D. (1991b). Interleukin-4 is important in protective immunity to a gastrointestinal nematode infection in mice. Proc. Natl. Acad. Sci. USA, 188, 551-554.

Urban, J. F., Jr., Noben-Trauth, N., Donaldson, D. D., Madden, K. B., Morris, S. C., Collins, M., \& Finkelman, F. D. (1998). IL-13, IL-4R alpha, and Stat6 are required for the expulsion of the gastrointestinal nematode parasite Nippostrongylus brasiliensis. Immunity, 8, 225-264.

Van den Brom, R., Moll, L., Kappert, C., Vellema, P., 2015. Haemonchus contortus resistance to monepantel in sheep. Vet. Parasitol. 209, 278-280.

Van Rijt, L., Richthofen, H. \& Ree, R. (2016). Type 2 innate lymphoid cells: at the cross-roads in allergic asthma. Seminars in immunopathology. Vol. 38. No. 4. Springer Berlin Heidelberg.

Van Panhuys, N., et al. (2011). Basophils are the major producers of IL-4 during primary helminth infection. The J. Immunol., 186(5), 2719-2728.

Vietta, E. S., Ohara, J., Myers, C. D., Layton, J. E., Krammer, P. H., \& Paul, W. E. (1985). Serological, biochemical and functional identity of B cell stimulatory factor-1 and B cell differentiation factor IgG1. J. Exp. Med., 162, 1726-1731.

Vono, M., Lin, A., Norrby-Teglund, A., Koup, R. A., Liang, F., \& Loré, K. (2017). Neutrophils acquire the capacity for antigen presentation to memory CD4 T cells in vitro and ex vivo. Blood, 129(14), 1991-2001. doi:10.1182/blood-2016-10-744441

Waller, P. J., \& Prichard, R. K. (1986). Drug resistance in nematodes. In Chemotherapy of Paraistic Diseases (Campbell, W.C. and Rew, R.S. eds), pp. 339-362, Plenum Press

WHO. World Health Report. World Health Organization; Geneva, Switzerland: 1999.

Wynn, T. A. (2003). Il-13 Effector functions. Annual Review of Immunology, 21(1), 425456. doi:10.1146/annurev.immunol.21.120601.14114 